\author{
Universidade de São Paulo \\ Programa de Pós Graduação Interunidades Bioengenharia \\ Escola de Engenharia de São Carlos \\ Faculdade de Medicina de Ribeirão Preto \\ Instituto de Química de São Carlos
}

Caio Sadao Medeiros Komino

\begin{abstract}
Análise eletromiográfica da fase inicial da autopropulsão de cadeira de rodas manual
\end{abstract}





\title{
Análise eletromiográfica da fase inicial da autopropulsão de cadeira de rodas manual
}

\author{
Dissertação apresentado ao Programa de Pós- \\ Graduação Interunidades Bioengenharia - \\ Escola de Engenharia de São Carlos / \\ Faculdade de Medicina de Ribeirão Preto / \\ Instituto de Química de São Carlos da \\ Universidade de São Paulo como parte dos \\ requisitos para obtenção do título de mestre \\ em Ciências.
}

Área de concentração: Bioengenharia Orientador: Prof. Dr. José Marques Novo Jr.

São Carlos 
AUTORIZO A REPRODUÇ̃̃O TOTAL OU PARCIAL DESTE TRABALHO, POR QUALQUER MEIO CONVENCIONAL OU ELETRÔNICO, PARA FINS DE ESTUDO E PESQUISA, DESDE QUE CITADA A FONTE.

Komino, Caio Sadao Medeiros
K75a Análise eletromiográfica da fase inicial da autopropulsão de cadeira de rodas manual / Caio Sadao Medeiros Komino; orientador José Marques Novo Júnior. São Carlos, 2017.

Dissertação (Mestrado) - Programa de Pós-Graduação Interunidades em Bioengenharia e Área de Concentração em Bioengenharia -- Escola de Engenharia de São Carlos; Faculdade de Medicina de Ribeirão Preto; Instituto de Química de São Carlos, da Universidade de São Paulo, 2017 .

1. propulsão. 2. impulso inicial. 3. propulsão inicial. 4. autopropulsão. 5. cadeira de rodas. 6. normalização. 7. eletromiografia. I. Título. 


\section{RESUMO}

KOMINO, C.S.M. Análise eletromiográfica da fase inicial da autopropulsão de cadeira de rodas manual. 2017. 70 f. Dissertação de Mestrado. Programa de Pós-Graduação Interunidades Bioengenharia - Escola de Engenharia de São Carlos / Faculdade de Medicina de Ribeirão Preto / Instituto de Química de São Carlos da Universidade de São Paulo, 2017.

Propulsionar cadeira de rodas (CR) está relacionado a altas incidências de dores e lesões em usuários de cadeira de rodas (UCR). Embora seja reconhecida como uma forma de baixa eficiência para se locomover, representa fundamental importância para o desempenho dessas pessoas nas atividades de vida diária, ocupacionais, de lazer e em sua participação social. Ao longo dos estudos sobre a propulsão nas últimas décadas, foi notado recentemente em especial, que a propulsão inicial que retira o sistema usuário-cadeira de rodas do repouso, o colocando em movimento, apresentam a maiores solicitações mecânicas. Considerando que esta situação é executada várias vezes durante o uso típico da cadeira de rodas, torna-a relevante objeto de estudo. Como até o momento, pouco foram os estudos sobre a fase inicial da autopropulsão e que do ponto de vista da neuroativação, esse movimento não foi abordado, este estudo tem como objetivo descrever o gesto da fase inicial da autopropulsão de cadeira de rodas manual de UCR, por meio da eletromiografia, apresentando os níveis atingidos de ativação muscular e o perfil do comportamento de ativação ao longo da execução do gesto da autopropulsão. Para isso foram avaliados oito grupos musculares envolvidos nesse gesto de onze UCR. Os sinais eletromiográficos foram coletados dos oito grupos musculares, simultaneamente, durante a execução de dez propulsões, partindo do repouso, de cada UCR participante da pesquisa. Com relação aos níveis de ativações musculares, foi introduzido um método alternativo de normalização. Esse método consiste na realização do teste de contração isométrica máxima na própria CR. Os resultados foram apresentados em boxplot a fim de demonstrar o pico de ativação bem como a distribuição dos demais níveis de ativação. Como o novo método proposto demonstrou limitações, inviabilizou a interpretação dos resultados quanto as intensidades calculadas. Sobre o perfil de acionamento muscular ao longo da execução da autopropulsão, os resultados foram expostos em gráficos normalizados pelo pico dinâmico e em relação ao período de um ciclo de propulsão, evidenciando o comportamento ativado em cada instante do ciclo. Segundo os resultados dessa segunda metodologia, entre os oito grupos musculares examinados, os que apresentaram os maiores 
picos de ativação foram: deltoide anterior $(80,27 \%)$, o peitoral maior $(79,27 \%)$, os flexores de punho $(78,93 \%)$ e os extensores de punho (80,65\%). Os achados colaboram com estudos anteriores de outros autores de que os principais grupos musculares efetores na propulsão de CR são o deltóide anterior (DA) e peitoral maior (PM).

Palavras chaves: Propulsão. Impulso inicial. Propulsão inicial. Autopropulsão. Cadeira de rodas. Normalização. Eletromiografia. 


\section{ABSTRACT}

KOMINO, C.S.M. Electromyographic analysis of the initial stage of wheelchair propulsion. 2017. 70 f. Dissertação de Mestrado. Programa de Pós-Graduação Interunidades Bioengenharia - Escola de Engenharia de São Carlos / Faculdade de Medicina de Ribeirão Preto / Instituto de Química de São Carlos da Universidade de São Paulo, 2017.

Propelling wheelchair (CR) is related to high incidences of pain and injury in wheelchair users (WCU). Although this locomotion way be known as low efficient locomotion mode, it represents fundamental importance for these people performance in daily living activities, occupational, leisure and in their social participation. Over the studies course on propulsion in recent decades, it has recently been noted, particularly, that the initial stage of wheelchair propulsion which retires the user-wheelchair system from resting, putting it into motion, presents greater mechanical stresses. It considering this situation is executed several times during the typical wheelchair usage, it makes this relevant study object. As until current moment, there are few studies about initial stage of wheelchair propulsion and, from the neuroactivation point of view, this movement was not approached, this study aims to describe the gesture of initial stage of manual wheelchair propulsion from WCU, across electromyography, presenting the muscular activation levels achieved and the recruited behavior profile during the propulsion gesture execution. For this problem, eight muscle groups involved in this gesture were evaluated from eleven WCU. Electromyographic signals were collected from these eight muscle groups, simultaneously, during ten propulsions execution, starting from resting, of each WCU participant of the research. Regarding the muscular activation levels, an alternative normalization method was introduced. This method consists in performing the maximum isometric contraction test on the wheelchair itself. The results were showed in boxplot in order to demonstrate the activation peak as well as the remaining activation levels distribution. As the new method proposed showed limitations, a better results interpretation was not possible on calculated intensities. Regarding the muscular activation profile during the propulsion execution, the results were exposed in graphs normalized by the dynamic peak as well as in relation to a single propulsion cycle, evidencing the activated behavior at each cycle moment. According to the results based on second methodology, among the eight muscle groups examined, the ones which presented the highest activation peaks values were: the anterior deltoid (80.27\%), the pectoralis major 
(79.27\%), the wrist flexors (78, 93\%) and the wrist extensors (80.65\%). The findings agree with previous studies by other authors that the main effector muscle groups in CR propulsion are anterior deltoid (DA) and pectoralis major (PM).

Key words: Propulsion. Initial impulse. Initial propulsion. Start-up propulsion. Self-propulsion. Wheelchair. Normalization. Electromyography. 
LISTA DE SIGLAS

CR - cadeira de rodas

UCR - usuário de cadeira de rodas

CIVM - contração isométrica voluntária máxima

RMS - root mean square

T - trapézio superior

DA - deltoide anterior

DP - deltoide posterior

PM - peitoral maior

BB - bíceps braquial

TB - tríceps braquial

FP - flexores de punho

EP - extensores de punho

CVintra - Coeficiente de variação intra participantes

CVinter - Coeficiente de variação inter participantes 



\section{LISTA DE FIGURAS}

Figura 1 - Representação do ciclo de propulsão na fase de tração.........................................24

Figura 2 - Posicionamento dos eletrodos afixados no participante......................................26

Figura 3 - Posições do teste de CIVM para realização das coletas de normalização.................27

Figura 4 - Níveis de ativações musculares normalizado pelo teste de CIVM na cadeira rodas na posição $A$ e na posição $B$ do participante 1

Figura 5 - Níveis de ativações musculares normalizado pelo teste de CIVM na cadeira rodas na posição $A$ e na posição $B$ do participante 2

Figura 6 - Níveis de ativações musculares normalizado pelo teste de CIVM na cadeira rodas na posição $A$ e na posição $B$ do participante 3

Figura 7 - Níveis de ativações musculares normalizado pelo teste de CIVM na cadeira rodas na posição $A$ e na posição $B$ do participante 4

Figura 8 - Níveis de ativações musculares normalizado pelo teste de CIVM na cadeira rodas na posição $A$ e na posição $B$ do participante 5

Figura 9 - Níveis de ativações musculares normalizado pelo teste de CIVM na cadeira rodas na posição $A$ e na posição $B$ do participante 6

Figura 10 - Níveis de ativações musculares normalizado pelo teste de CIVM na cadeira rodas na posição $A$ e na posição $B$ do participante 7

Figura 11 - Níveis de ativações musculares normalizado pelo teste de CIVM na cadeira rodas na posição $A$ e na posição $B$ do participante 8

Figura 12 - Níveis de ativações musculares normalizado pelo teste de CIVM na cadeira rodas na posição $A$ e na posição $B$ do participante 9

Figura 13 - Níveis de ativações musculares normalizado pelo teste de CIVM na cadeira rodas na posição $A$ e na posição $B$ do participante 10

Figura 14 - Níveis de ativações musculares normalizado pelo teste de CIVM na cadeira rodas na posição $A$ e na posição $B$ do participante 11

Figura 15 - Níveis de ativações musculares da amostra normalizado pelo teste de CIVM na cadeira rodas na posição $A$ e na posição $B$.

Figura 16 - Representação gráfica dos valores calculados do coeficiente de variação

intra participantes (CVintra) agrupados por participante.

Figura 17 - Representação gráfica dos valores calculados do coeficiente de variação inter participantes (CVinter) agrupados por grupo muscular. .40

Figura 18 - Ativação muscular do trapézio superior $(\mathrm{T})$ normalizado pelo pico dinâmico 
e normalizado pelo ciclo de uma propulsão.

Figura 19 - Ativação muscular do deltóide anterior (DA) normalizado pelo pico dinâmico e normalizado pelo ciclo de uma propulsão.

Figura 20 - Ativação muscular do deltoide posterior (DP) normalizado pelo pico dinâmico e normalizado pelo ciclo de uma propulsão.

Figura 21 - Ativação muscular do peitoral maior (PM) normalizado pelo pico dinâmico e normalizado pelo ciclo de uma propulsão.

Figura 22 - Ativação muscular do bíceps braquial (BB) normalizado pelo pico dinâmico e normalizado pelo ciclo de uma propulsão.

Figura 23 - Ativação muscular do tríceps braquial (TB) normalizado pelo pico dinâmico e normalizado pelo ciclo de uma propulsão.

Figura 24 - Ativação muscular dos flexores de punho (FP) normalizado pelo pico dinâmico e normalizado pelo ciclo de uma propulsão.

Figura 25 - Ativação muscular dos extensores de punho (EP) normalizado pelo pico dinâmico e normalizado pelo ciclo de uma propulsão. .45

Figura 26 - Representação gráfica dos valores calculados do coeficiente de variação inter participantes (CVinter) agrupados por grupo muscular do total da amostra. 


\section{LISTA DE EQUAÇÕES}

Coeficiente de variação intra participantes:

$$
\mathrm{CV}=\sqrt{\mathrm{MSE}} / \overline{\mathrm{X}} \text {, sendo MSE a média do erro quadrado. }
$$

Coeficiente de variação inter participantes:

$$
\mathrm{CV}=\mathrm{sD} / \overline{\mathrm{X}}
$$





\section{LISTA DE TABELAS}

Tabela 1 - Caracterização dos participantes da pesquisa.

Tabela 2 - Valores de normalização calculados na posição A (30 graus posterior ao top do aro)

Tabela 3 - Valores de normalização calculados na posição B (topo do aro) .28

Tabela 4 - Valores calculados do coeficiente de variação intra participantes (CVintra) para cada grupo muscular de cada participante

Tabela 5 - Valores calculados do coeficiente de variação inter participantes (CVinter) para cada grupo muscular de cada participante. .40

Tabela 6 - Valores calculados do coeficiente de variação inter participantes (CVinter) por grupo muscular do total da amostra 



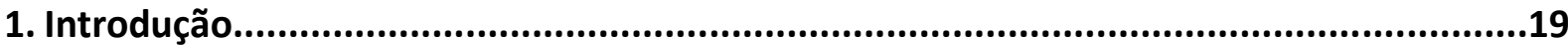

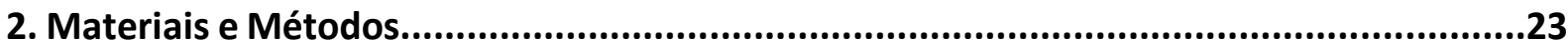

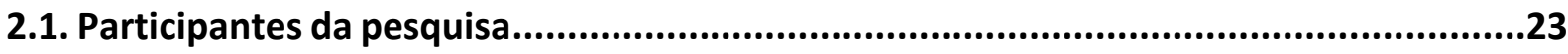

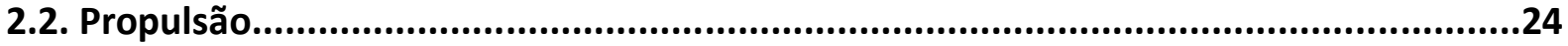

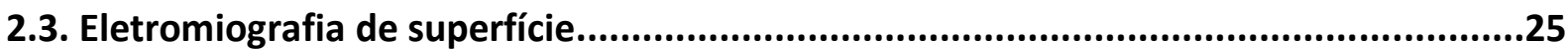

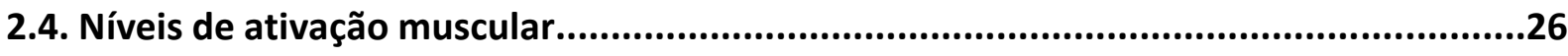

2.5. Teste da contração isométrica voluntária máxima.....................................................27

2.6. Perfil da ativação muscular ao longo de uma propulsão............................................29

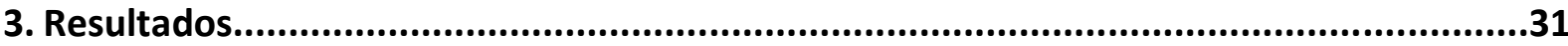

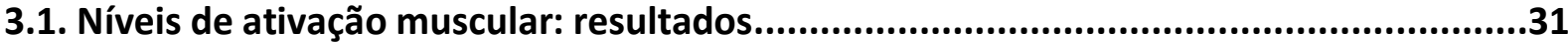

3.2. Perfil da ativação muscular ao longo de uma propulsão: resultados............................41

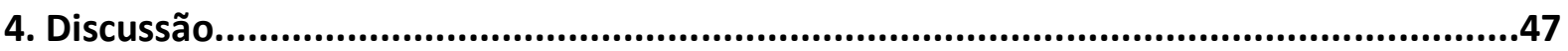

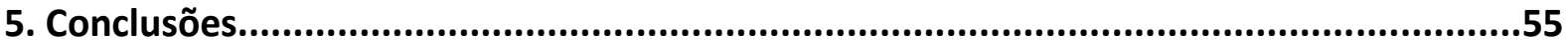

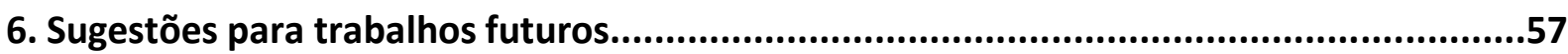

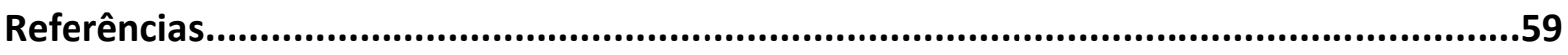

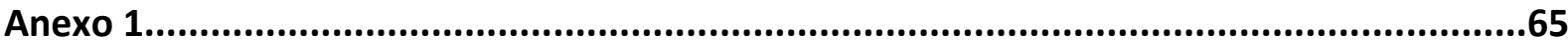

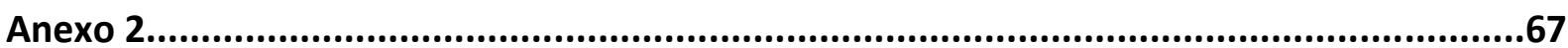






\section{Introdução}

Dores e lesões associadas a membros superiores de usuários de cadeira de rodas (UCR) manual são comuns, sendo relatadas altas incidências nessa população (BONINGER et al., 2003; DYSON-HUDSON; KIRSHBLUM, 2004; MCCASLAND et al., 2006). Isso relaciona-se com o fato de que essas pessoas além das tarefas habituais do cotidiano, também dependem dos membros superiores para sua locomoção. Embora seja reconhecida como uma forma de baixa eficiência para se locomover (KOTAJARVI et al., 2006; VEEGER; VAN DER WOUDE; ROZENDAL, 1992), representa fundamental importância para o desempenho dessas pessoas nas atividades de vida diária, ocupacionais, de lazer e em sua participação social (ORGANIZAÇÃO MUNDIAL DA SAÚDE - OMS, 2011). Mobilidade esta que é inerente ao ato de propulsionar a cadeira de rodas (CR). Ao propulsionar-se, as maiores exigências mecânicas nos membros superiores são observadas na fase de contato das mãos com os aros, quando o usuário aplica forca para se autopropulsionar (ARNET et al., 2013; DYSON-HUDSON; KIRSHBLUM, 2004; MERCER et al., 2006; VAN DRONGELEN et al., 2005; VEEGER; ROZENDAAL; VAN DER HELM, 2002). Portanto, estudar a autopropulsão mostra-se relevante à medida que possibilita contribuir no entendimento deste movimento, visando melhor preservação na funcionalidade dos membros superiores assim como na elaboração de diretrizes ergonômicas em cadeira de rodas (CR).

A propulsão da cadeira de rodas aparece como objeto de estudo desde a década de 70, mas foi nos anos 2000 quando se aumentou o volume de pesquisas. No início as limitações quanto aos estudos se davam por analisar a propulsão sem o deslocamento de fato: sobre uma esteira ou em um ergômetro em forma de CR estacionário (DABONNEVILLE et al., 2005; MOSS; FOWLER; GOOSEY-TOLFREY, 2005; VANLANDEWIJCK; THEISEN; DALY, 2001). Tais limitações prejudicavam melhores interpretações pois quando era avaliado sobre uma esteira, o UCR propulsionava de forma alterada se preocupando em não encostar nas bordas da esteira. Situação análoga acontecia ao se propulsionar em CR estacionária. Era conferido uma estabilidade maior em relação as reais condições do gesto.

Além disso, os estudos focaram-se mais na situação em que a cadeira já se encontra em movimento, i.e. "estado de manutenção". Pouco se atentava para a 
propulsão que inicia o deslocamento, retirando o sistema usuário-cadeira de rodas do repouso.

Com relação a esta propulsão de início do deslocamento, alguns pesquisadores realizaram estudos descrevendo a respeito do modo de uso típico da CR entre os UCR (SONENBLUM; SPRIGLE; LOPEZ, 2012; TOLERICO et al., 2007). Constatou-se que a frequência de inícios e paradas em sua condução é muito alta, aumentando ainda mais quando encontram-se em suas casas. No entanto, é justamente nessa situação onde são reportadas as maiores quantidades de estresse mecânico (KLOOSTERMAN et al., 2015; KOONTZ et al., 2005, 2009). Isso posto e considerando esse gesto como um dos mais executados na rotina dos UCR, torna-se necessário estudar a fase inicial da autopropulsão.

Em um estudo mais recente sobre a fase inicial da autopropulsão de CR, comparando modelos com geração de força assistida a modelos regulares manuais (KLOOSTERMAN et al., 2016), os autores comentaram da pouca importância dada até então por diretrizes clínicas sobre este assunto e concluíram que o mesmo deve ser mais investigado.

Em razão do fato de que são poucos os estudos abordando este específico gesto nesta condição inicial, principalmente sobre o solo, sem uso de ergômetros e com real deslocamento, este trabalho preocupa-se em descrever a fase inicial da autopropulsão de cadeira de rodas manual de UCR. Acrescentado a isso, no que se refere à neuroativação, até este momento não foi apresentado o comportamento muscular da fase inicial da autopropulsão. Por isso, este estudo pretende explorar informações, a partir da eletromiografia, sobre quais são os níveis de ativação muscular, desta específica propulsão e como ela se apresenta durante cada período ao longo das excursões articulares envolvidas neste movimento.

A respeito da eletromiografia, estudos que utilizaram esta técnica, apresentaram formas diferentes de normalização. Em sua maioria normalizam pelo teste de contração isométrica voluntária máxima (CIVM). Entretanto na aquisição dos dados de normalização, são observadas diferenças quanto aos exercícios isométricos aplicados durante o teste. Alguns autores baseiam-se nos exercícios descritos por Nieminen, Takala e Vlikari-Juntura (1993) e Westgaard (1988). Estes defendem que as posturas executadas no teste, fiquem no meio do arco de movimento possível de cada 
articulação. Neste caso gera uma maior imprecisão devido a indefinição do meio do arco de movimento da articulação. Além disso, a comparação entre participantes, devido as características de flexibilidade serem diferentes, não permitiria uma adequada interpretação visto que cada um executaria em condições mecânicas diferentes.

Já outros autores se baseiam em exercícios específicos para cada grupo muscular como os apresentados por Boettcher, Ginn e Cathers (2008) e Kelly et al. (1996). O aspecto favorável nesta situação é a padronização, porém ao aplicarmos esta metodologia em UCR torna-se complicada devido as transferências e manipulações, posto que alguns exercícios necessitam estar deitados ou sentados fora da CR.

Sendo assim, este estudo propõe um novo método de normalização para dados eletromiográficos de propulsão da CR. Este método introduz uma forma de aquisição dos dados de normalização, onde o teste CIVM é realizado na própria cadeira de rodas. Trava-se as rodas, para não ocorrer um deslocamento, enquanto o UCR aplica força ao aro como se intencionasse propulsioná-la a frente. O mesmo procedimento é realizado duas vezes em pontos distintos do aro de propulsão: no topo do aro e outro posterior a este ponto em trinta graus. Com isso, além de facilitar as coletas evitando transferências da CR e maiores manipulações com os UCR, espera-se favorecer uma melhor interpretação dos dados visto que a postura é mais próxima ao gesto estudado.

Embora seja conhecido que várias características da CR como, ajustes da cadeira de rodas (BONINGER et al., 2002; COWAN et al., 2009; MEDOLA et al., 2014), posicionamento do eixo da roda traseira (BERTOLACCINI et al., 2017; BONINGER et al., 2000; KOTAJARVI et al., 2004) e diferentes resistências de rolamentos (BASCOU et al., 2013, KWARCIAK et al., 2009; VAN DER WOUDE et al., 2003), podem vir a dificultar a interpretação dos dados, foi decidido que durante o experimento todos os UCR utilizariam suas próprias CR. Uma vez que ao utilizar uma mesma cadeira, esta não estaria ajustada as dimensões antropométricas de cada participante. Outra prevista limitação, prévia as coletas, acontece quanto ao eletromiógrafo, pois o equipamento utilizado não permite sincronizar a outro sistema.

Assim, este estudo tem como objetivo descrever o gesto da fase inicial da autopropulsão de cadeira de rodas manual de UCR, por meio da eletromiografia, apresentando os níveis atingidos de ativação muscular e o perfil do comportamento de ativação ao longo da execução do gesto da autopropulsão. 


\section{Materiais e Métodos}

\subsection{Participantes da pesquisa}

Participaram do estudo 11 pessoas com deficiência, usuários de cadeiras de rodas ativos, sem histórico de lesão/disfunção articular persistente e/ou trauma musculoesquelético associado aos membros superiores, com no mínimo dois anos de uso da CR e capazes de realizarem a autopropulsão. Todos relataram ter lesão medular incompleta.

Os participantes, assim que concordaram em submeter-se a pesquisa, foram explicados sobre os procedimentos da coleta de dados e assinaram o Termo de Consentimento Livre e Esclarecido (TCLE) (ANEXO 1). O estudo foi aprovado pelo Comitê de Ética da Universidade Federal de São Carlos com parecer número 1.608.547.

A amostra foi caracterizada conforme a Tabela 1. Cada participante utilizou sua própria cadeira de rodas com suas próprias configurações de ajuste. Nenhuma delas apresentou cambagem nas rodas traseiras e todas eram de estrutura de bloco único rígidas. Todos os participantes referiram o braço direito como membro dominante.

Tabela 1 - Caracterização dos participantes da pesquisa.

\begin{tabular}{lllllllllll}
\hline Participante & $\begin{array}{l}\text { Idade } \\
\text { (anos) }\end{array}$ & Sexo & $\begin{array}{l}\text { Peso } \\
(\mathrm{kg})\end{array}$ & $\begin{array}{l}\text { Estatura } \\
(\mathrm{m})\end{array}$ & $\begin{array}{l}\text { YE } \\
(\mathrm{cm})\end{array}$ & $\begin{array}{l}\text { XE } \\
(\mathrm{cm})\end{array}$ & $\begin{array}{l}\text { LA } \\
(\mathrm{cm})\end{array}$ & $\begin{array}{l}\text { EA } \\
(\mathrm{cm})\end{array}$ & $\begin{array}{l}\text { ES } \\
(\mathrm{cm})\end{array}$ & Diagnóstico \\
\hline 1 & 48 & $\mathrm{M}$ & 80 & 1,78 & 72 & 6 & 38 & 59 & 30 & Paraplegia \\
2 & 32 & $\mathrm{M}$ & 85 & 1,68 & 67 & 4 & 44 & 58 & 30 & Paraplegia \\
3 & 31 & $\mathrm{M}$ & 56 & 1,70 & 69 & 3 & 38 & 57 & 30 & Tetraplegia \\
4 & 39 & $\mathrm{M}$ & 70 & 1,79 & 78 & 6 & 39 & 54 & 30 & Paraplegia \\
5 & 52 & $\mathrm{~F}$ & 62 & 1,51 & 71 & 3 & 42 & 58 & 30 & Paraplegia \\
6 & 49 & $\mathrm{~F}$ & 65 & 1,57 & 71 & 6 & 41 & 57 & 30 & Paraplegia \\
7 & 47 & $\mathrm{M}$ & 80 & 1,74 & 74 & 2 & 44 & 60 & 30 & Paraplegia \\
8 & 35 & $\mathrm{M}$ & 70 & 1,75 & 77 & 9 & 42 & 59 & 30 & Tetraplegia \\
9 & 25 & $\mathrm{~F}$ & 59 & 1,68 & 67 & 7 & 46 & 67 & 29 & Paraplegia \\
10 & 41 & $\mathrm{~F}$ & 59 & 1,65 & 66 & 5 & 44 & 61 & 30 & Tetraplegia \\
11 & 23 & $\mathrm{M}$ & 65 & 1,78 & 72 & 2 & 45 & 59 & 30 & Paraplegia \\
\hline
\end{tabular}

Legenda: M - Masculino; F - Feminino; YE - Distância vertical entre o processo acromial e o eixo das rodas traseiras da cadeira de rodas no plano sagital; XE - Distância horizontal entre a base do encosto e o eixo das rodas traseiras da cadeira de rodas no plano sagital; LA - Largura do assento da cadeira de rodas; EA - Distância entre os aros de propulsão; EA - Distância vertical entre o eixo das rodas traseiras da cadeira de rodas e o solo. Fonte: Elaborada pelo autor. 


\subsection{Propulsão}

O ciclo completo de propulsão na cadeira de rodas compreende duas fases: a fase de tração e a fase de recuperação. A fase de tração é o período em que o UCR aplica força aos aros das rodas, sendo todo o trecho em que as mãos estão em contato com o aro. Já a fase de recuperação é o período em que as mãos soltam dos aros e realiza trajetória no ar até novo posicionamento para início do próximo ciclo.

Este estudo concentra-se apenas na fase de tração da propulsão, já que o enfoque pretendido é iminente ao período que sucede o início do deslocamento, retirando o sistema usuário-cadeira de rodas do repouso (velocidade zero).

Inicia-se com a posição estática colocando as mãos nos aros das rodas e preparando para o movimento. Em seguida o usuário executa a propulsão aplicando força nos aros a fim de deslocar-se a frente, até o final da propulsão quando o usuário solta as mãos dos aros das rodas. Este ciclo foi coletado repetindo-se 10 vezes em cada participante. A instrução aos participantes foi de que realizassem a propulsão o mais forte e o mais rápido possível.

Figura 1- Representação do ciclo de propulsão na fase de tração.

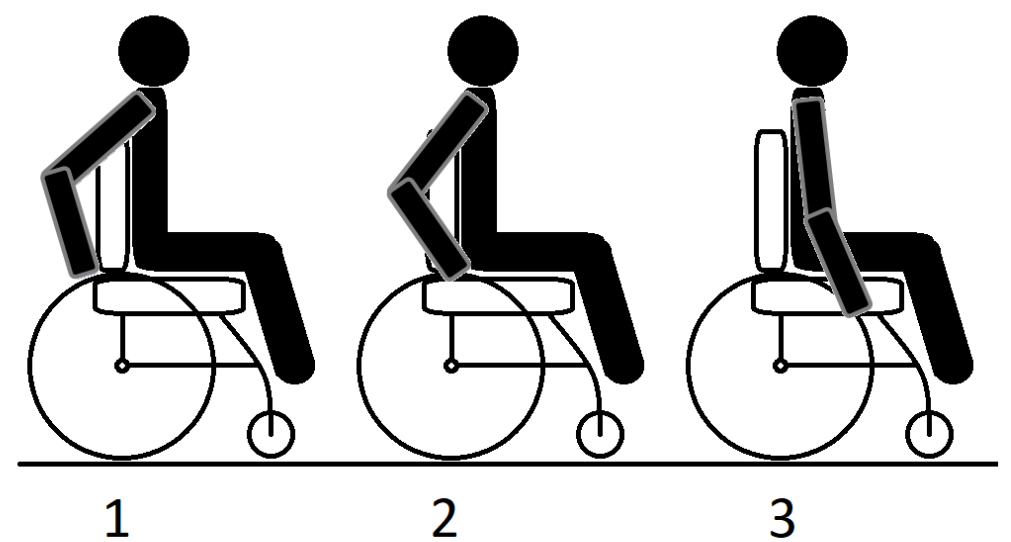

Legenda: No instante 1 o participante posiciona as mãos nos aros de propulsão para dar início ao movimento (início do ciclo). No instante 2 o participante mantém contato com os aros aplicando força e já se encontra em movimento o sistema usuário - cadeira de rodas. No instante 3 o participante inicia abandono das mãos ao aro das rodas caracterizando o fim do ciclo aqui abordado. Fonte: Elaborado pelo autor. 


\subsection{Eletromiografia de superfície}

Os sinais eletromiográficos brutos (ANEXO 2) foram coletados no membro dominante durante as 10 propulsões partindo do repouso de cada participante. Foi utilizado um eletromiógrafo portátil da marca Miotec - Miotool Wireless (Miotec Equipamentos Biomédicos, Porto Alegre, Brasil) e eletrodos de pino aço inoxidável $\mathrm{AgCl}$ da marca $3 M$.

Para caracterização dos resultados objetivados nesta pesquisa, foram selecionadas duas formas de apresentação dispondo cada uma com as respectivas metodologias de normalização:

a) níveis de ativação muscular normalizados pelo teste de CIVM;

b) perfil da ativação muscular ao longo de uma propulsão normalizados pelo método do pico dinâmico (BURDEN; BARTLETT, 1999) e pelo tempo de um ciclo de propulsão.

A fim de reduzir possíveis interferências na aquisição do sinal EMG, anteriormente a cada avaliação os voluntários foram submetidos à preparação da pele com tricotomização e limpeza da área com álcool a 70\%. Em seguida os eletrodos foram posicionados sobre cada grupo muscular e fixados com tiras esparadrapo, para evitar seu deslocamento durante a realização dos procedimentos. Foram detectados sinais de EMG de oito grupos musculares: deltóide anterior (DA), deltóide posterior (DP), peitoral maior (PM), trapézio superior (T), bíceps braquial (BB), tríceps braquial (TB), flexores (FP) e extensores (EP) de punho (Figura 2). Todos no lado do membro dominante de cada participante, respeitando-se os locais para posicionamento padronizado pelo European Recommendations for Surface Electromyography (SENIAN) e aproximadamente alinhados com a direção das fibras musculares. O eletrodo de referência, monopolar, foi posicionado no processo espinhoso da vértebra C7 conforme indicações de uso do referido equipamento (MioTool - MioTec System). 
Figura 2 - Posicionamento dos eletrodos afixados no participante.

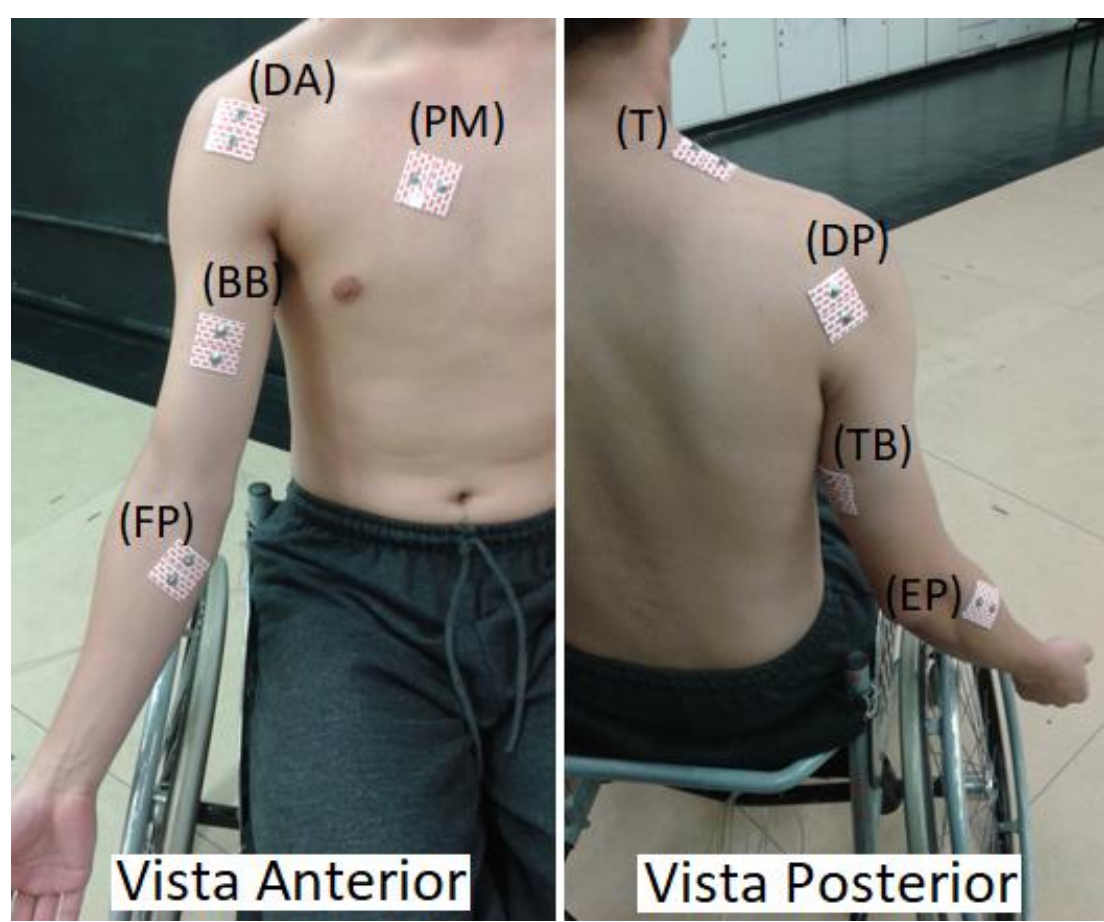

Legenda: Na vista anterior mostra os pontos afixados pelos eletrodos no deltoide anterior (DA), peitoral maior (PM), bíceps braquial (BB) e flexores do punho (FP). Na vista posterior mostra os pontos afixados pelos eletrodos no trapézio superior (T), deltoide posterior (DP), tríceps braquial (TB) e extensores do punho (EP).

Fonte: Elaborada pelo autor.

As curvas do sinal eletromiográfico foram analisados por meio de um algoritmo desenvolvido em linguagem Matlab $^{\circledR}$ (Software Matlab R2009a), cuja licença foi adquirida pelo projeto APQ-01284/09 da FAPEMIG/MG/Brasil.

\subsection{Níveis de ativação muscular}

Uma das formas propostas neste estudo quanto a exposição dos resultados, corresponde ao nível de ativação muscular de cada um dos 8 grupos musculares avaliados no gesto da autopropulsão inicial. Para esta metodologia, após a coleta dos sinais brutos, o participante realizou uma outra coleta em esforço isométrico máximo em duas posições distintas (Teste da CIVM; posição A e posição B). A partir dos dados obtidos no teste de CIVM, calculou-se os valores de normalização e definiu-se os níveis de ativação muscular de cada propulsão. 


\subsection{Teste da contração isométrica voluntária máxima}

Esta pesquisa intenciona introduzir uma proposta de um método de normalização para os dados eletromiográficos da autopropulsão manual de cadeira de rodas. Os valores tomados como referência (Tabela 2; Tabela 3), para então normalização, são calculados a partir de um teste de contração isométrica máxima realizando esforço na própria cadeira de rodas. Assim, o participante sentado em sua própria CR, travada e impedida de deslocar-se, aplica força nos aros no sentido de propulsionar a cadeira para frente por 6 segundos, originando contrações isométricas nos grupos musculares avaliados. Este procedimento foi repetido 3 vezes em cada posição previamente selecionada: posição A e posição B (Figura 3).

Figura 3 - Posições do teste de CIVM para realização das coletas de normalização.

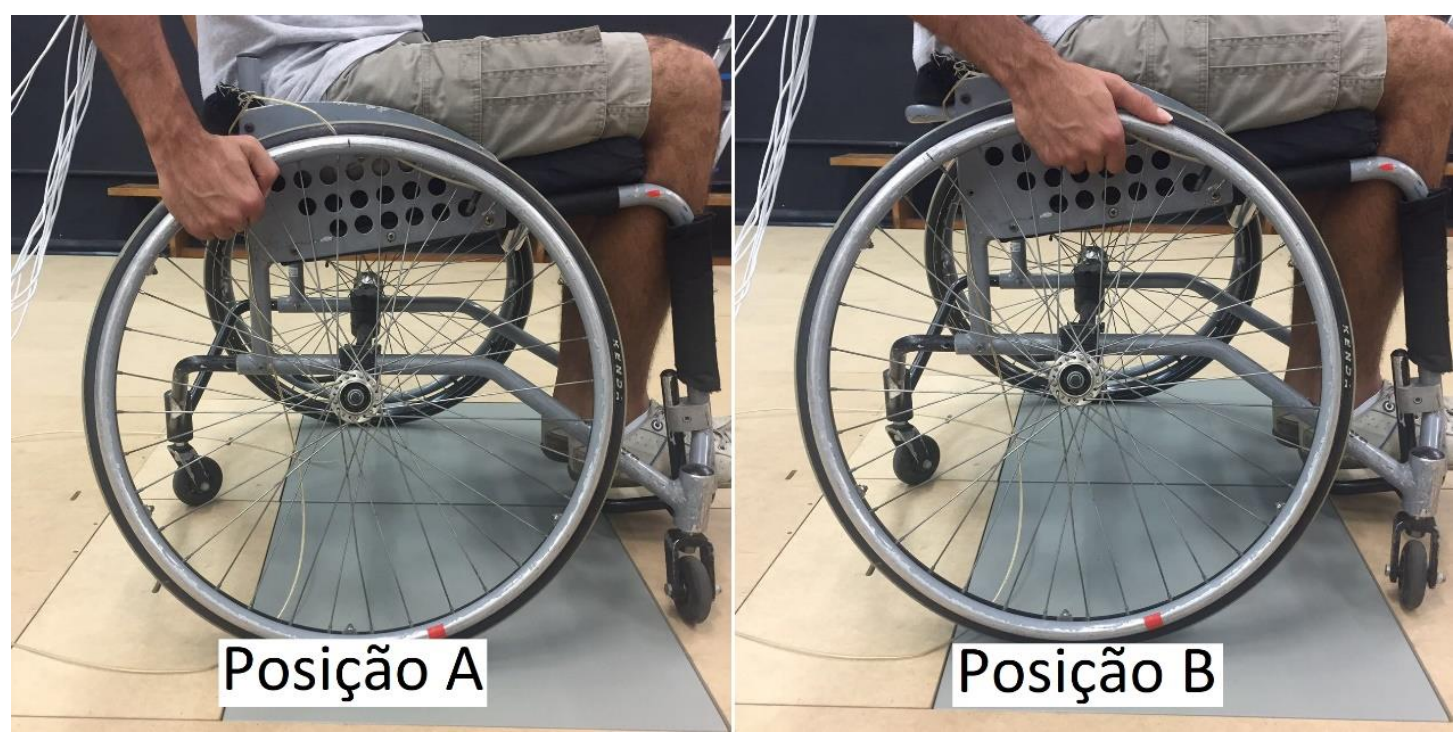

Legenda: Na esquerda a mão está na posição A. Na direita, está posicionada em B. Fonte: Elaborada pelo autor. 
Tabela 2 - Valores de normalização calculados na posição A (30 graus posterior ao topo do aro).

\begin{tabular}{ccccccccc}
\hline \multicolumn{7}{c}{ Valores de Normalização em A $(\mu \mathrm{V})$} \\
Participante & T & DA & DP & PM & BB & TB & FP & EP \\
\hline 1 & 388,50 & 367,94 & 176,29 & 431,49 & 700,88 & 54,79 & 137,81 & 150,21 \\
2 & 26,38 & 164,20 & 30,93 & 173,60 & 330,55 & 73,44 & 302,01 & 132,47 \\
3 & 334,83 & 1575,03 & 94,25 & 1130,79 & 716,91 & 403,91 & 304,45 & 375,65 \\
4 & 168,46 & 207,42 & 189,98 & 404,65 & 370,12 & 44,10 & 272,68 & 236,15 \\
5 & 66,35 & 448,53 & 118,55 & 116,93 & 195,28 & 112,93 & 305,45 & 66,52 \\
6 & 80,78 & 36,64 & 15,43 & 58,56 & 102,51 & 30,99 & 91,26 & 95,31 \\
7 & 40,62 & 108,58 & 98,25 & 334,44 & 114,31 & 46,08 & 262,68 & 207,75 \\
8 & 57,49 & 399,16 & 33,56 & 343,52 & 158,28 & 89,78 & 278,63 & 91,30 \\
9 & 481,07 & 215,85 & 332,05 & 220,20 & 295,34 & 57,39 & 199,85 & 211,73 \\
10 & 327,68 & 414,34 & 251,54 & 192,92 & 271,22 & 75,15 & 341,15 & 205,26 \\
11 & 453,42 & 118,21 & 438,41 & 430,51 & 597,29 & 118,20 & 845,55 & 190,60 \\
\hline
\end{tabular}

Legenda de siglas: trapézio superior (T); deltoide anterior (DA); deltoide posterior (DP); peitoral maior (PM); bíceps braquial (BB); tríceps braquial (TB); flexores de punho (FP); extensores de punho (EP). Fonte: Elaborada pelo autor.

Tabela 3 - Valores de normalização calculados na posição B (topo do aro).

\begin{tabular}{ccccccccc}
\hline \multicolumn{7}{c}{ Valores de Normalização em B $(\mu \mathrm{V})$} \\
Participante & T & DA & DP & PM & BB & TB & FP & EP \\
\hline 1 & 228,49 & 408,77 & 115,00 & 503,23 & 419,32 & 252,70 & 121,90 & 167,53 \\
2 & 82,43 & 127,57 & 33,12 & 118,22 & 387,65 & 35,51 & 329,20 & 102,01 \\
3 & 894,40 & 985,46 & 298,31 & 645,34 & 943,11 & 98,29 & 351,03 & 432,50 \\
4 & 214,06 & 442,96 & 166,66 & 457,72 & 524,58 & 100,05 & 277,90 & 161,78 \\
5 & 77,39 & 77,51 & 45,34 & 64,65 & 299,53 & 36,56 & 190,25 & 56,22 \\
6 & 18,08 & 105,57 & 11,52 & 98,92 & 21,91 & 16,63 & 66,49 & 164,98 \\
7 & 39,83 & 29,94 & 122,10 & 171,55 & 129,15 & 46,39 & 173,49 & 227,21 \\
8 & 76,89 & 477,16 & 54,14 & 290,21 & 181,02 & 365,55 & 202,32 & 99,62 \\
9 & 364,49 & 59,59 & 411,41 & 63,45 & 159,83 & 95,86 & 201,21 & 161,13 \\
10 & 198,81 & 653,63 & 127,62 & 246,08 & 186,04 & 134,49 & 276,24 & 166,85 \\
11 & 207,10 & 266,94 & 172,77 & 866,17 & 459,76 & 261,49 & 785,19 & 318,34 \\
\hline
\end{tabular}

Legenda de siglas: trapézio superior (T); deltoide anterior (DA); deltoide posterior (DP); peitoral maior (PM); bíceps braquial (BB); tríceps braquial (TB); flexores de punho (FP); extensores de punho (EP). Fonte: Elaborada pelo autor.

Na posição A, coloca-se a mão de modo que o 3ํ metacarpo se sobreponha a um ponto do aro a 30 graus posterior ao ponto mais elevado do aro. Na posição B, o 3o metacarpo se sobrepõe ao ponto mais elevado do aro.

Os dados eletromiográficos brutos não foram retificados pois foram suavizados pelo método root mean square (RMS). Foi aplicado janelamento por overlapping de 150 ms. Devido a isso, o teste da CIVM teve descartado o primeiro e o último segundo 
coletado após suavização a fim de eliminar a deformação das extremidades. Portanto considerou-se os 4 segundos centrais do teste. Para o cálculo dos valores de normalização, efetuou-se a média entre os 3 testes de cada posição ( $A$ e B), assim encontrando os valores de normalização. O mesmo foi feito para o cálculo dos valores de normalização A e B em todos os grupos musculares.

\subsection{Perfil da ativação muscular ao longo de uma propulsão}

Uma segunda forma proposta neste estudo, corresponde a apresentação de um perfil de ativação dos grupos musculares, ao longo da excursão de um ciclo do gesto de propulsão inicial através de gráficos. Neste caso os dados foram suavizados da mesma forma como citado na seção anterior, normalizados pelo método do pico dinâmico e quanto ao tempo relativo de um ciclo de propulsão (BURDEN; BARTLETT, 1999). 


\section{Resultados}

Nesta seção os resultados foram divididos em duas partes. A primeira parte se refere aos níveis de ativação muscular normalizados pelo teste CIVM na cadeira de rodas. A segunda, relaciona-se a apresentação dos gráficos normalizados no pico e no tempo de um ciclo de propulsão.

\subsection{Níveis de ativação muscular: resultados}

Nas Figuras 4 ao 14 contém os níveis de ativação dos 8 grupos musculares avaliados em cada participante. Em todos, estão dispostos os dados do mesmo grupo muscular em pares, normalizados em A e B respectivamente.

Percebe-se em vários casos que os valores de pico ultrapassam o nível de $100 \%$. Apresentou mais vezes essa condição o TB normalizado na posição B (TB-B), em 9 situações. Na sequência os grupos musculares TB e EP normalizados em A (TB-A)(EP-A) com 8 casos, seguidos pelo T e os EP normalizados em B (T-B)(EP-B) com 7 vezes.

Frequências intermediárias dos valores pico acima dos 100\% foram observadas 6 vezes nos grupos DA e DP normalizados em ambas as posições (DA-A) (DA-B) (DP-A) (DP-B) e com 5 vezes nos grupos musculares T normalizado em A (T-A) e FP normalizado em A e B (FP-A) (FP-B). Menos ocorrências foram vistas no grupos musculares BB e PM, sendo 1 para BB normalizado em A (BB-A), 2 para BB normalizado em B (BB-B) e 3 para o PM normalizados em A e B (PM-A)(PM-B).

Com relação as medianas, nota-se que em alguns casos ela supera o nível de ativação de $50 \%$. Ocorrem 3 vezes nos grupos musculares T-B, DP-A, TB-B, 2 vezes em T-A, DA-A, DP-B e 1 vez em DA-B, PM-B, BB-B, TB-A e EP-B. Nos grupos musculares PMA, BB-A, FP-A, FP-B não tiveram casos da mediana superior a 50\%. A maior frequência foi apresentada pelo EP-A com 5 observações. 
Figura 4 - Níveis de ativações musculares normalizado pelo teste de CIVM na cadeira rodas na posição $\mathrm{A}$ e na posição B do participante 1.

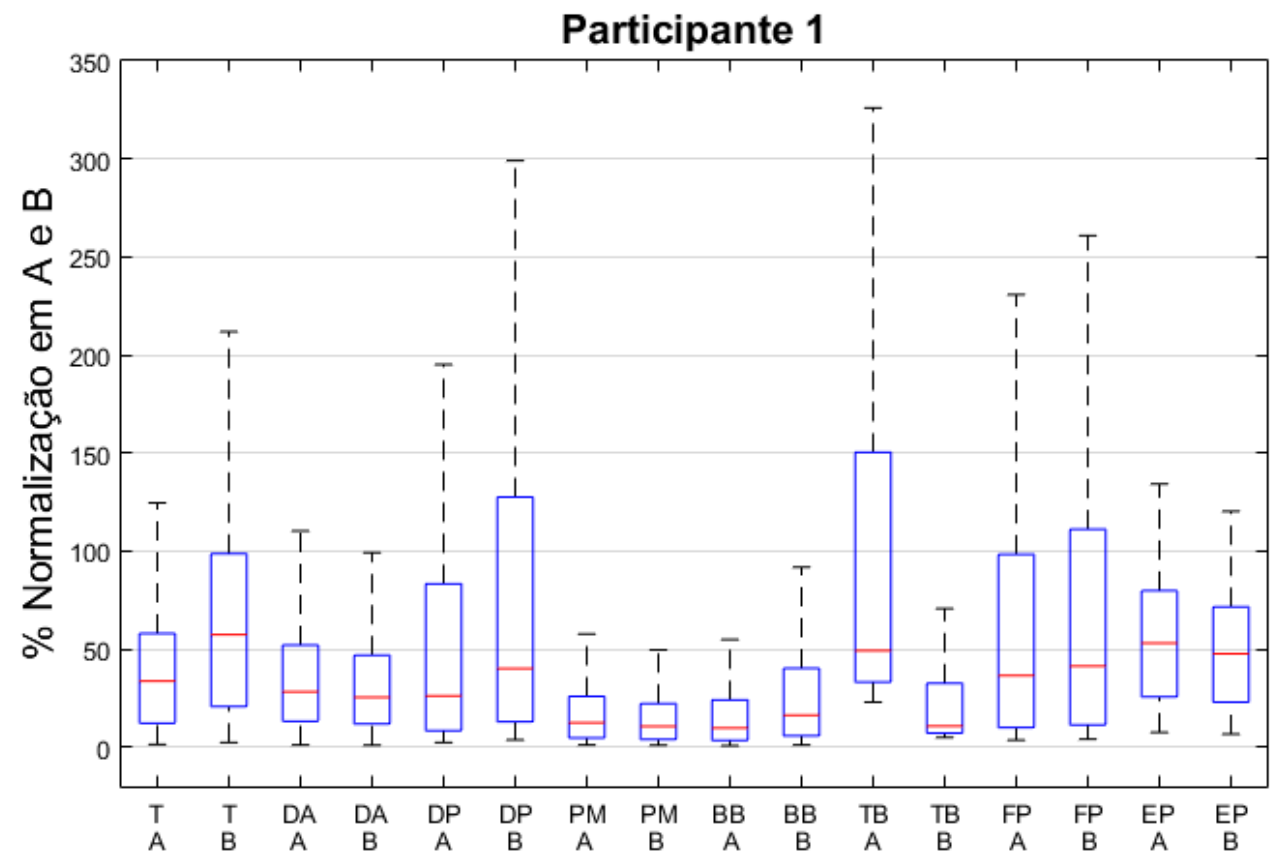

Legenda eixo horizontal, primeira linha: trapézio superior (T), deltoide anterior (DA), deltoide posterior (DP), peitoral maior (PM), bíceps braquial (BB), tríceps braquial (TB), flexores de punho (FP) e extensores de punho (EP); segunda linha: normalizado na posição $A(A)$ e normalizado na posição $B(B)$. Fonte: Elaborada pelo autor.

Figura 5 - Níveis de ativações musculares normalizado pelo teste de CIVM na cadeira rodas na posição $A$ e na posição $B$ do participante 2 .

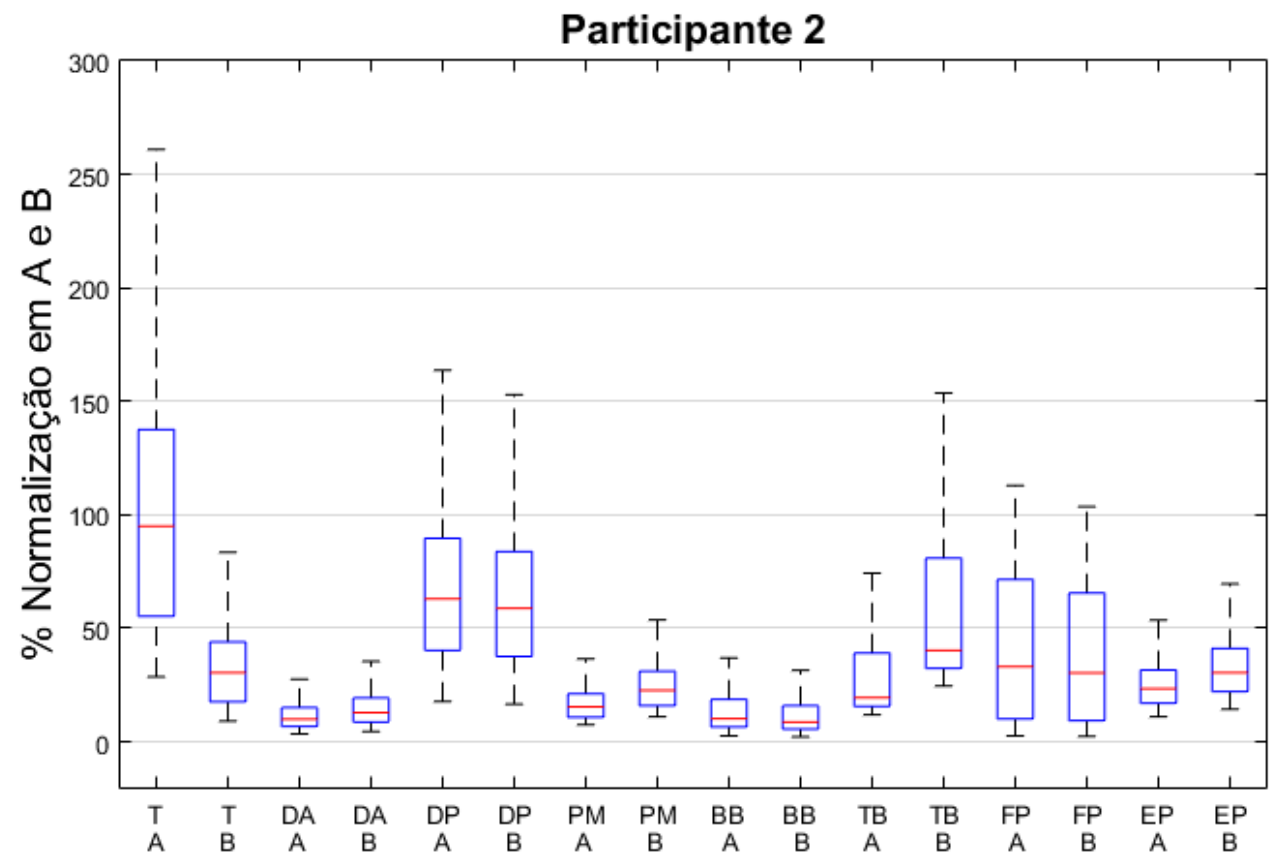

Legenda eixo horizontal, primeira linha: trapézio superior ( $T$ ), deltoide anterior (DA), deltoide posterior (DP), peitoral maior (PM), bíceps braquial (BB), tríceps braquial (TB), flexores de punho (FP) e extensores de punho (EP); segunda linha: normalizado na posição $A(A)$ e normalizado na posição $B(B)$.

Fonte: Elaborada pelo autor. 
Figura 6 - Níveis de ativações musculares normalizado pelo teste de CIVM na cadeira rodas na posição $\mathrm{A}$ e na posição $B$ do participante 3 .

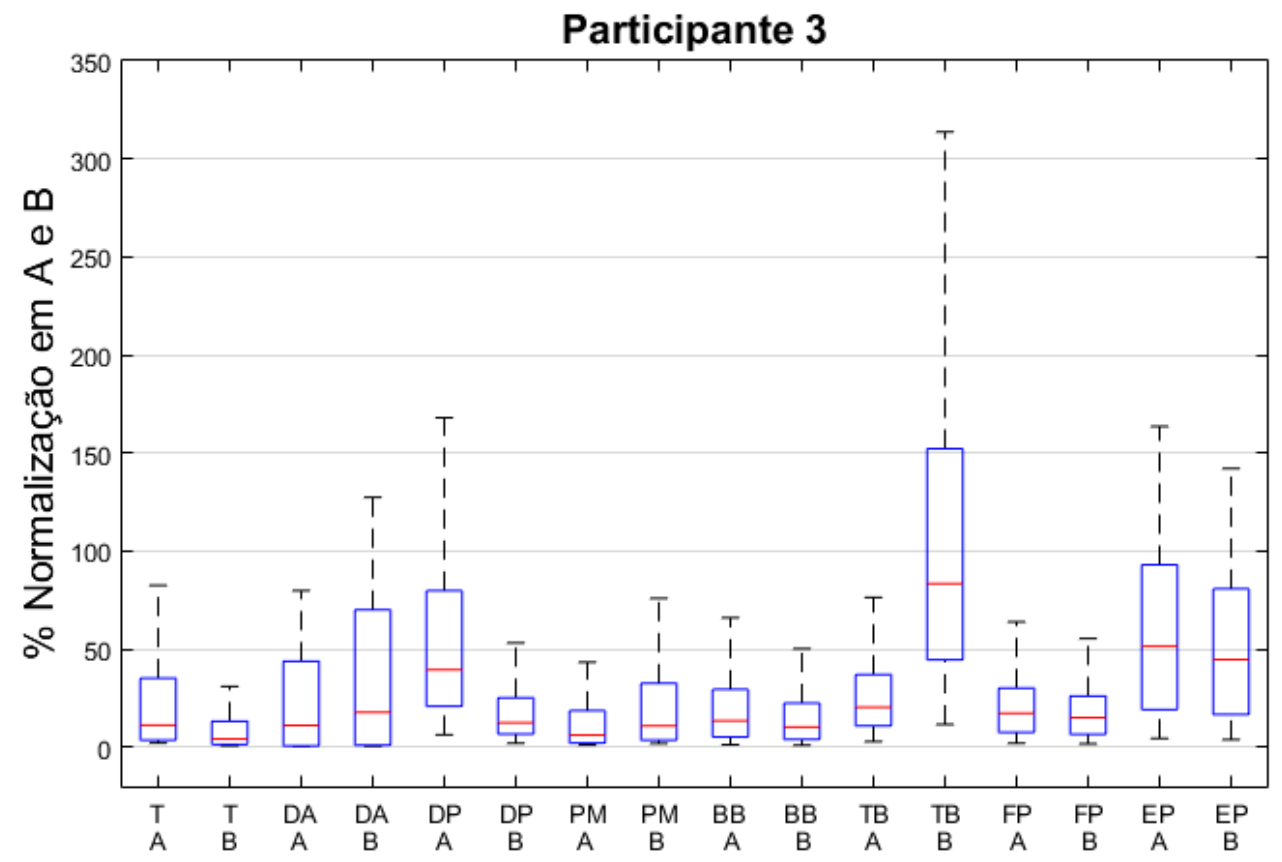

Legenda eixo horizontal, primeira linha: trapézio superior (T), deltoide anterior (DA), deltoide posterior (DP), peitoral maior (PM), bíceps braquial (BB), tríceps braquial (TB), flexores de punho (FP) e extensores de punho (EP); segunda linha: normalizado na posição $A(A)$ e normalizado na posição $B(B)$. Fonte: Elaborada pelo autor.

Figura 7 - Níveis de ativações musculares normalizado pelo teste de CIVM na cadeira rodas na posição A e na posição B do participante 4 .

\section{Participante 4}

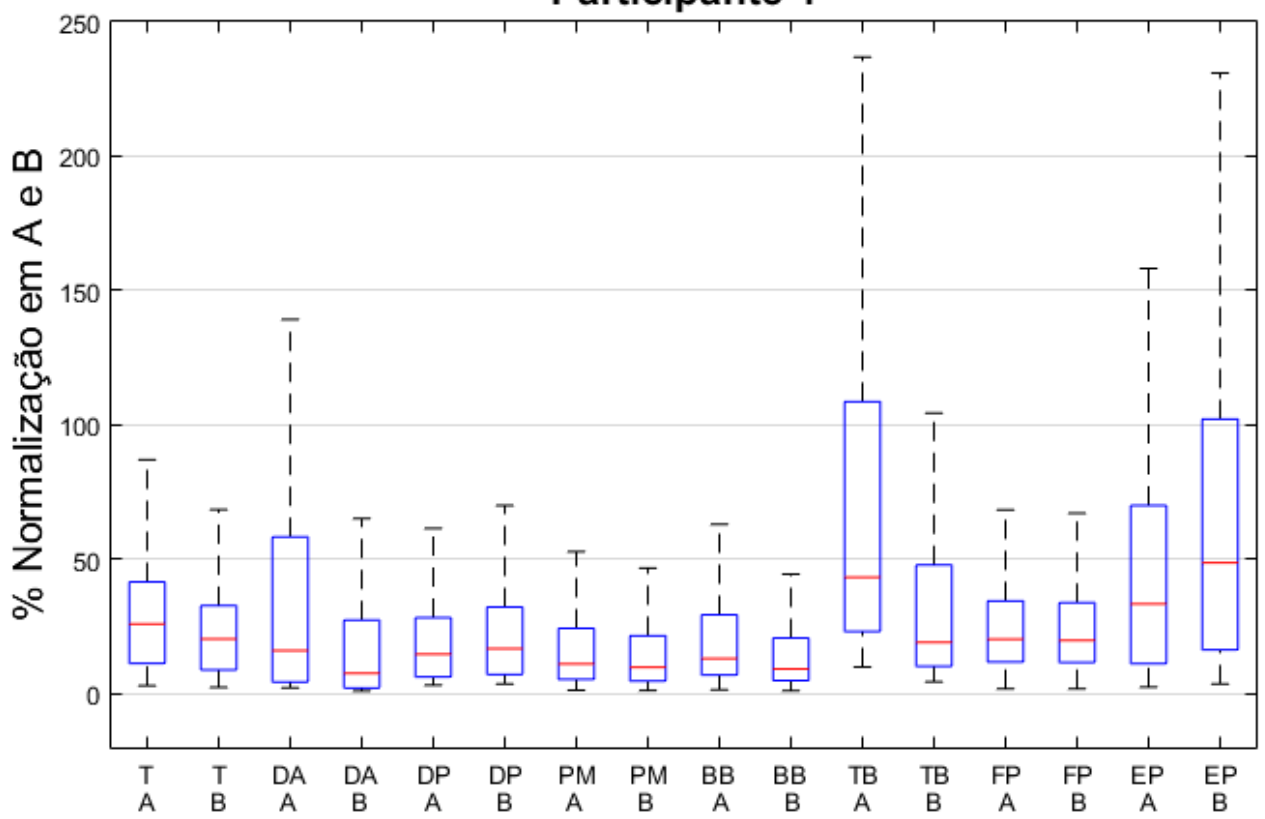

Legenda eixo horizontal, primeira linha: trapézio superior $(T)$, deltoide anterior (DA), deltoide posterior (DP), peitoral maior (PM), bíceps braquial (BB), tríceps braquial (TB), flexores de punho (FP) e extensores de punho (EP); segunda linha: normalizado na posição $A(A)$ e normalizado na posição $B(B)$. Fonte: Elaborada pelo autor. 
Figura 8 - Níveis de ativações musculares normalizado pelo teste de CIVM na cadeira rodas na posição A e na posição $B$ do participante 5 .

\section{Participante 5}

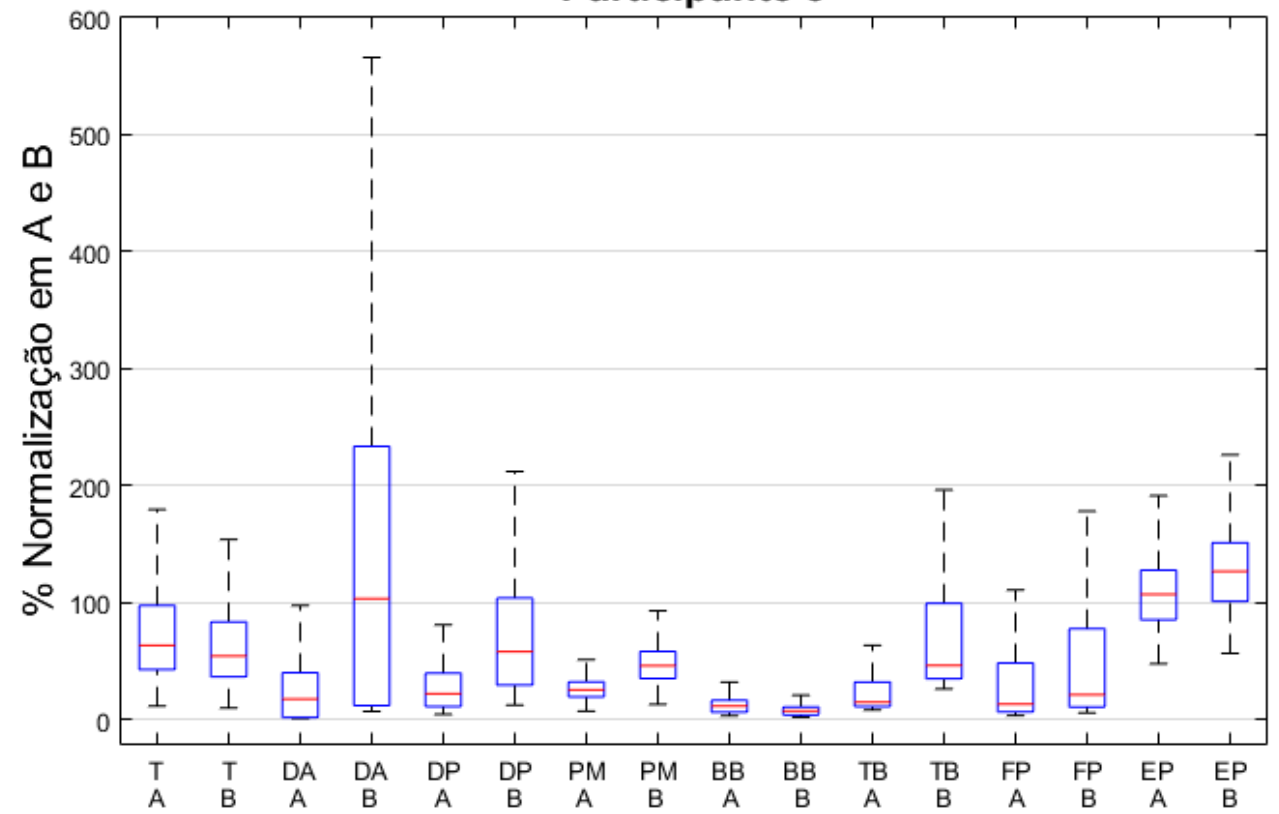

Legenda eixo horizontal, primeira linha: trapézio superior ( $T$ ), deltoide anterior (DA), deltoide posterior $(D P)$, peitoral maior (PM), bíceps braquial (BB), tríceps braquial (TB), flexores de punho (FP) e extensores de punho (EP); segunda linha: normalizado na posição $A(A)$ e normalizado na posição $B(B)$.

Fonte: Elaborada pelo autor.

Figura 9 - Níveis de ativações musculares normalizado pelo teste de CIVM na cadeira rodas na posição A e na posição B do participante 6 .

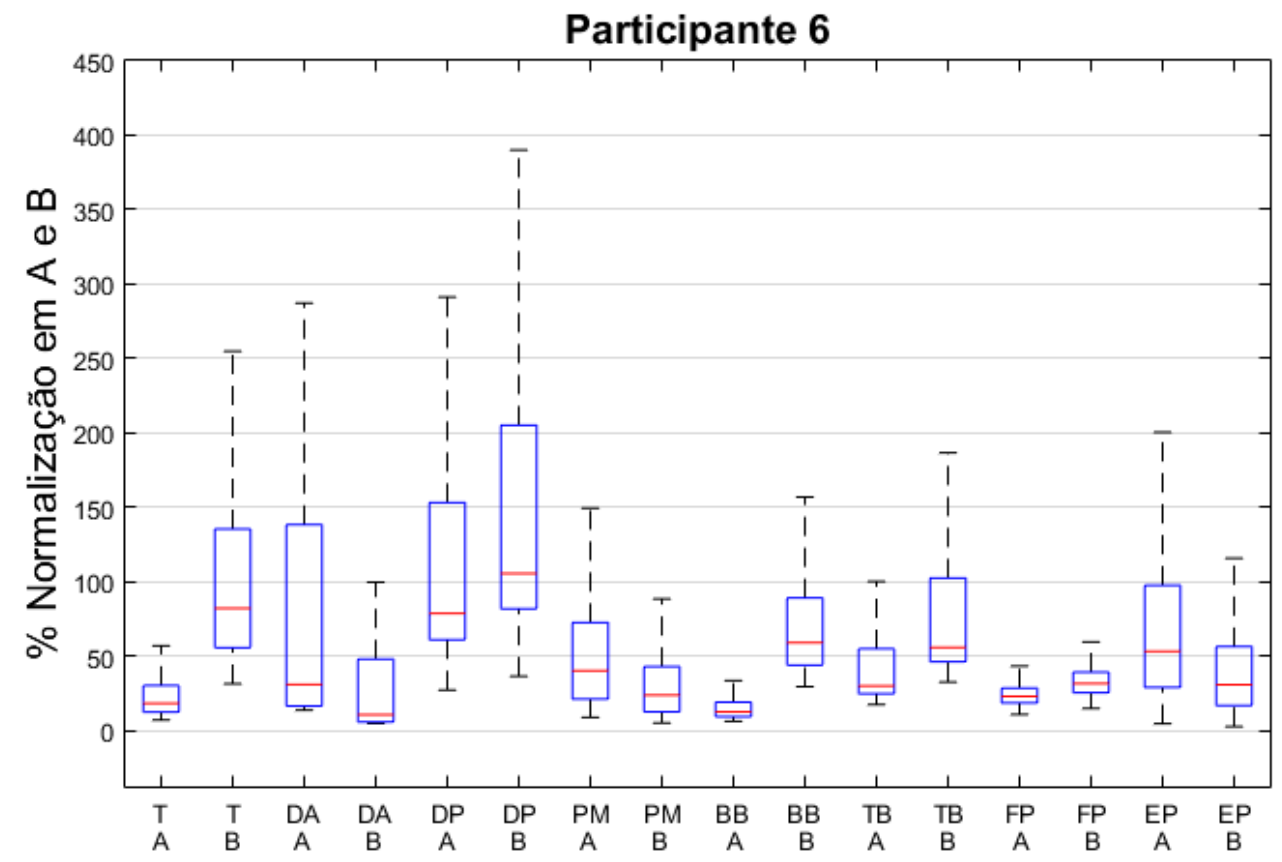

Legenda eixo horizontal, primeira linha: trapézio superior ( $T$ ), deltoide anterior (DA), deltoide posterior (DP), peitoral maior (PM), bíceps braquial (BB), tríceps braquial (TB), flexores de punho (FP) e extensores de punho (EP); segunda linha: normalizado na posição $A(A)$ e normalizado na posição $B(B)$. Fonte: Elaborada pelo autor. 
Figura 10 - Níveis de ativações musculares normalizado pelo teste de CIVM na cadeira rodas na posição A e na posição $B$ do participante 7 .

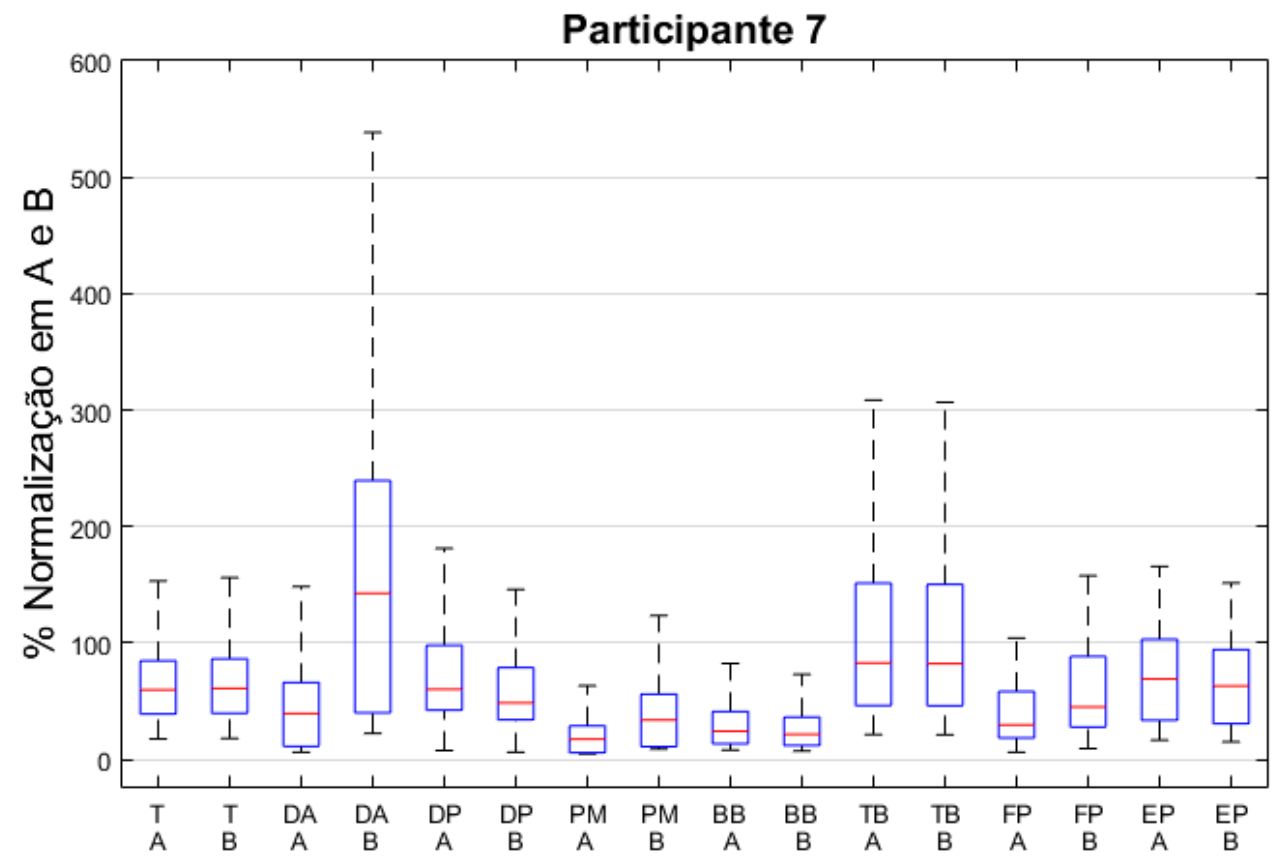

Legenda eixo horizontal, primeira linha: trapézio superior ( $T$ ), deltoide anterior (DA), deltoide posterior (DP), peitoral maior (PM), bíceps braquial (BB), tríceps braquial (TB), flexores de punho (FP) e extensores de punho (EP); segunda linha: normalizado na posição $A(A)$ e normalizado na posição $B(B)$.

Fonte: Elaborada pelo autor.

Figura 11 - Níveis de ativações musculares normalizado pelo teste de CIVM na cadeira rodas na posição A e na posição $B$ do participante 8 .

\section{Participante 8}

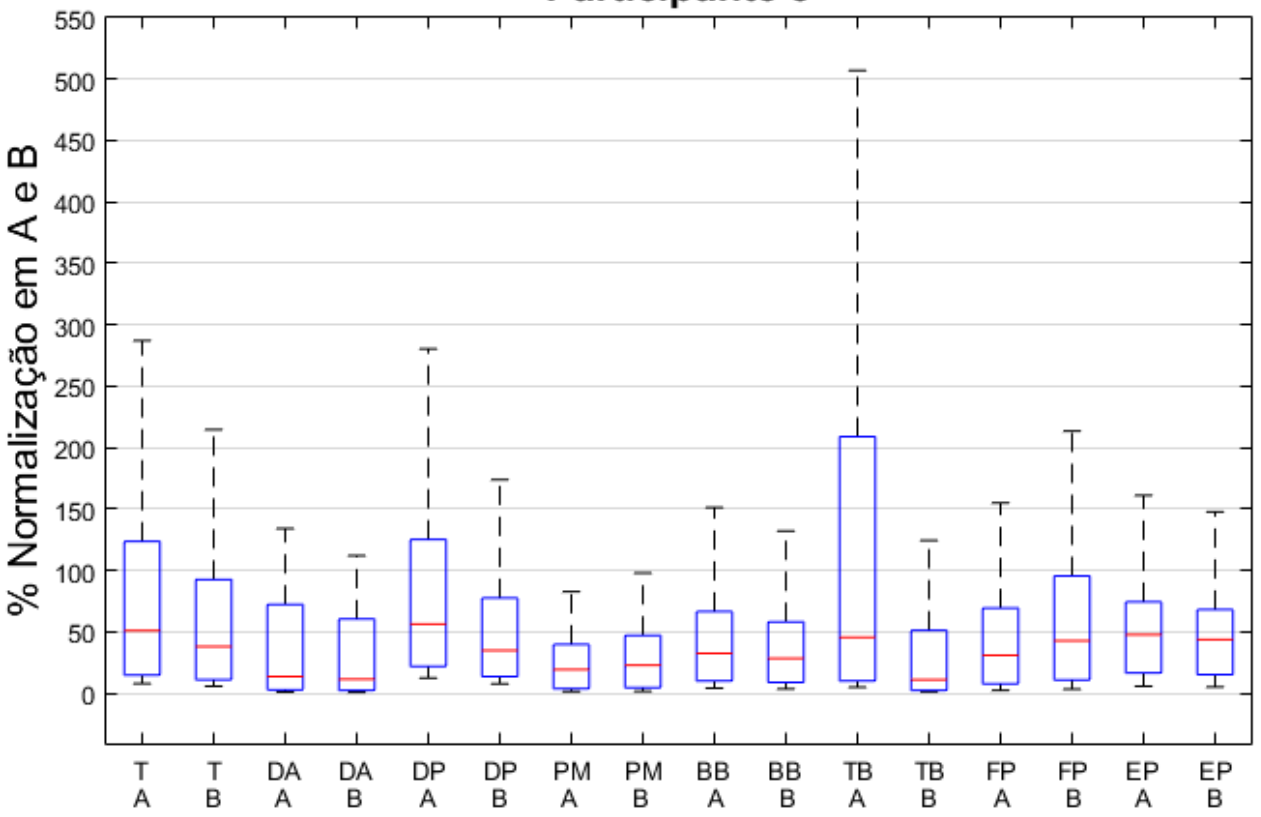

Legenda eixo horizontal, primeira linha: trapézio superior ( $T$ ), deltoide anterior (DA), deltoide posterior (DP), peitoral maior (PM), bíceps braquial (BB), tríceps braquial (TB), flexores de punho (FP) e extensores de punho (EP); segunda linha: normalizado na posição $A(A)$ e normalizado na posição $B(B)$.

Fonte: Elaborada pelo autor. 
Figura 12 - Níveis de ativações musculares normalizado pelo teste de CIVM na cadeira rodas na posição A e na posição B do participante 9 .

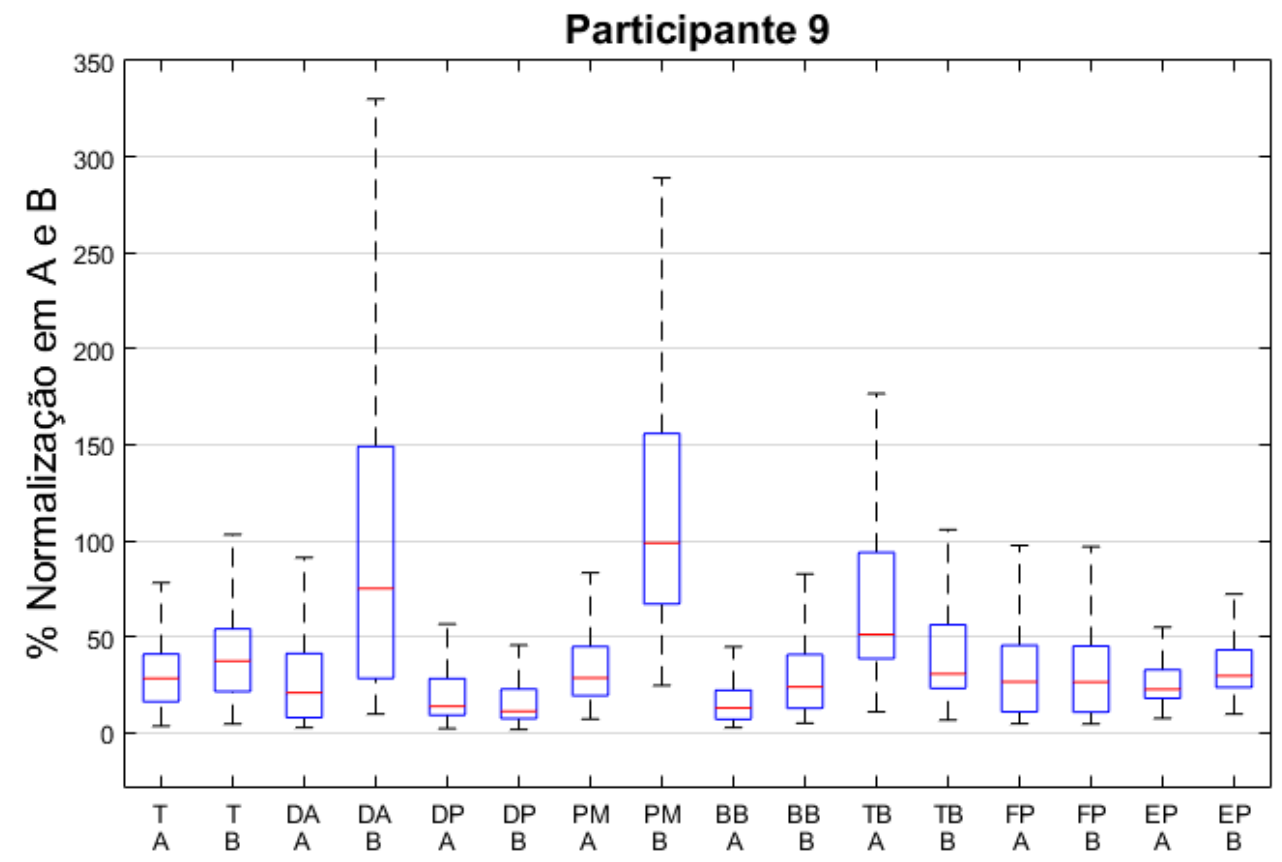

Legenda eixo horizontal, primeira linha: trapézio superior ( $T$ ), deltoide anterior (DA), deltoide posterior (DP), peitoral maior (PM), bíceps braquial (BB), tríceps braquial (TB), flexores de punho (FP) e extensores de punho (EP); segunda linha: normalizado na posição $A(A)$ e normalizado na posição $B(B)$. Fonte: Elaborada pelo autor.

Figura 13 - Níveis de ativações musculares normalizado pelo teste de CIVM na cadeira rodas na posição A e na posição $B$ do participante 10.

\section{Participante 10}

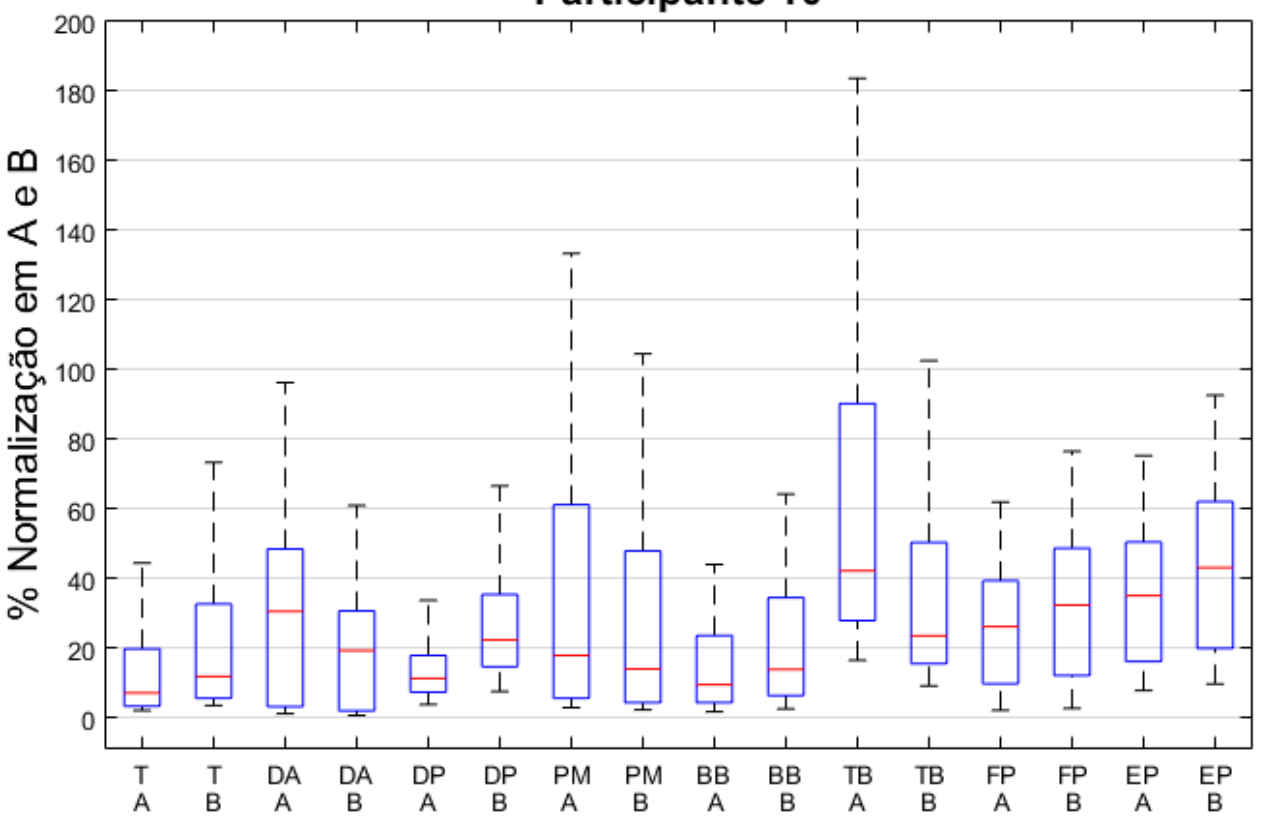

Legenda eixo horizontal, primeira linha: trapézio superior (T), deltoide anterior (DA), deltoide posterior (DP), peitoral maior (PM), bíceps braquial (BB), tríceps braquial (TB), flexores de punho (FP) e extensores de punho (EP); segunda linha: normalizado na posição $A(A)$ e normalizado na posição $B(B)$. Fonte: Elaborada pelo autor. 
Figura 14 - Níveis de ativações musculares normalizado pelo teste de CIVM na cadeira rodas na posição A e na posição $B$ do participante 11.

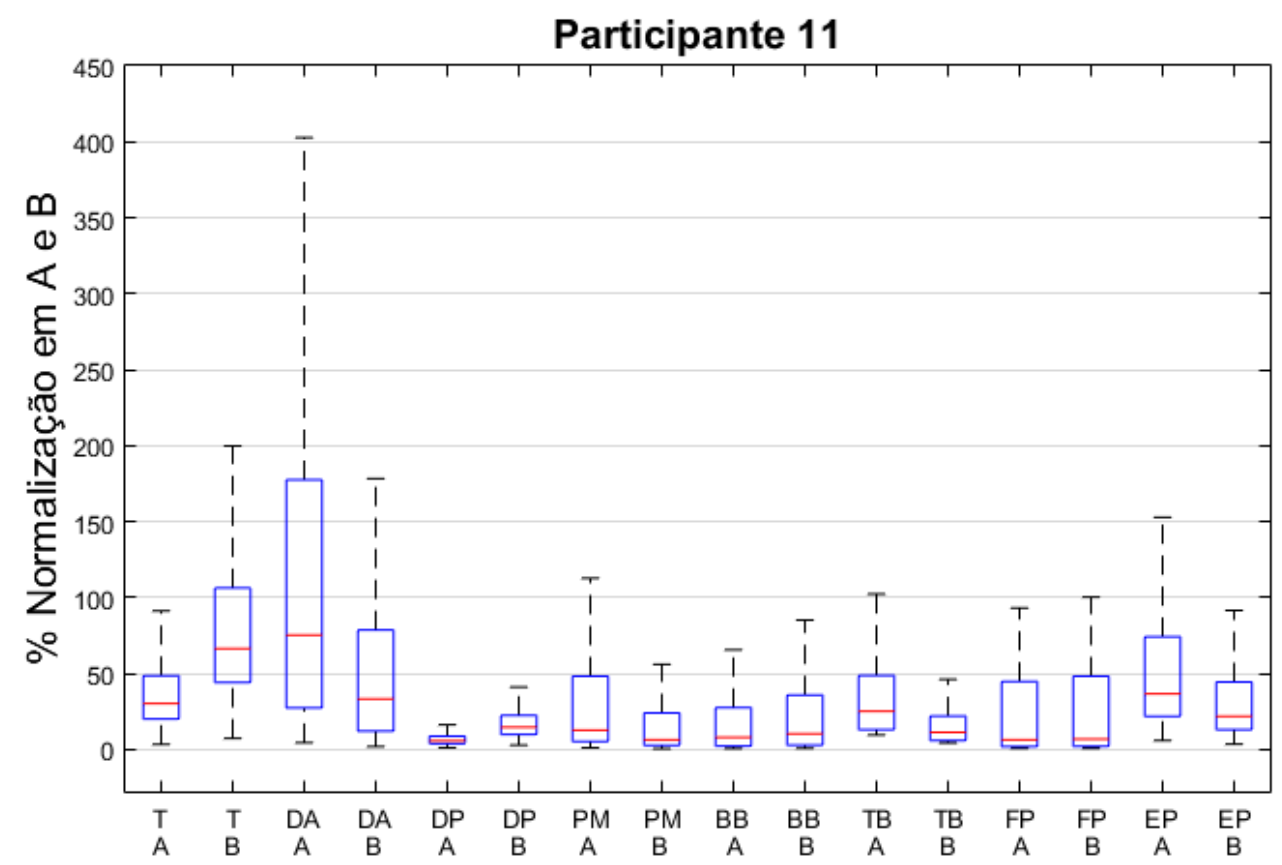

Legenda eixo horizontal, primeira linha: trapézio superior ( $T$ ), deltoide anterior (DA), deltoide posterior (DP), peitoral maior (PM), bíceps braquial (BB), tríceps braquial (TB), flexores de punho (FP) e extensores de punho (EP); segunda linha: normalizado na posição $A(A)$ e normalizado na posição $B(B)$. Fonte: Elaborada pelo autor.

A Figura 15 mostra os resultados de todos os participantes reunidos por grupo muscular dispostos em pares respectivamente normalizados nas posições A e B. Foi verificado que em nenhum grupo muscular foi observado a mediana acima do $50 \%$ da normalização, assim como o terceiro quartil ultrapassando o $100 \%$. 
Figura 15 - Níveis de ativações musculares da amostra normalizado pelo teste de CIVM na cadeira rodas na posição $A$ e na posição $B$.

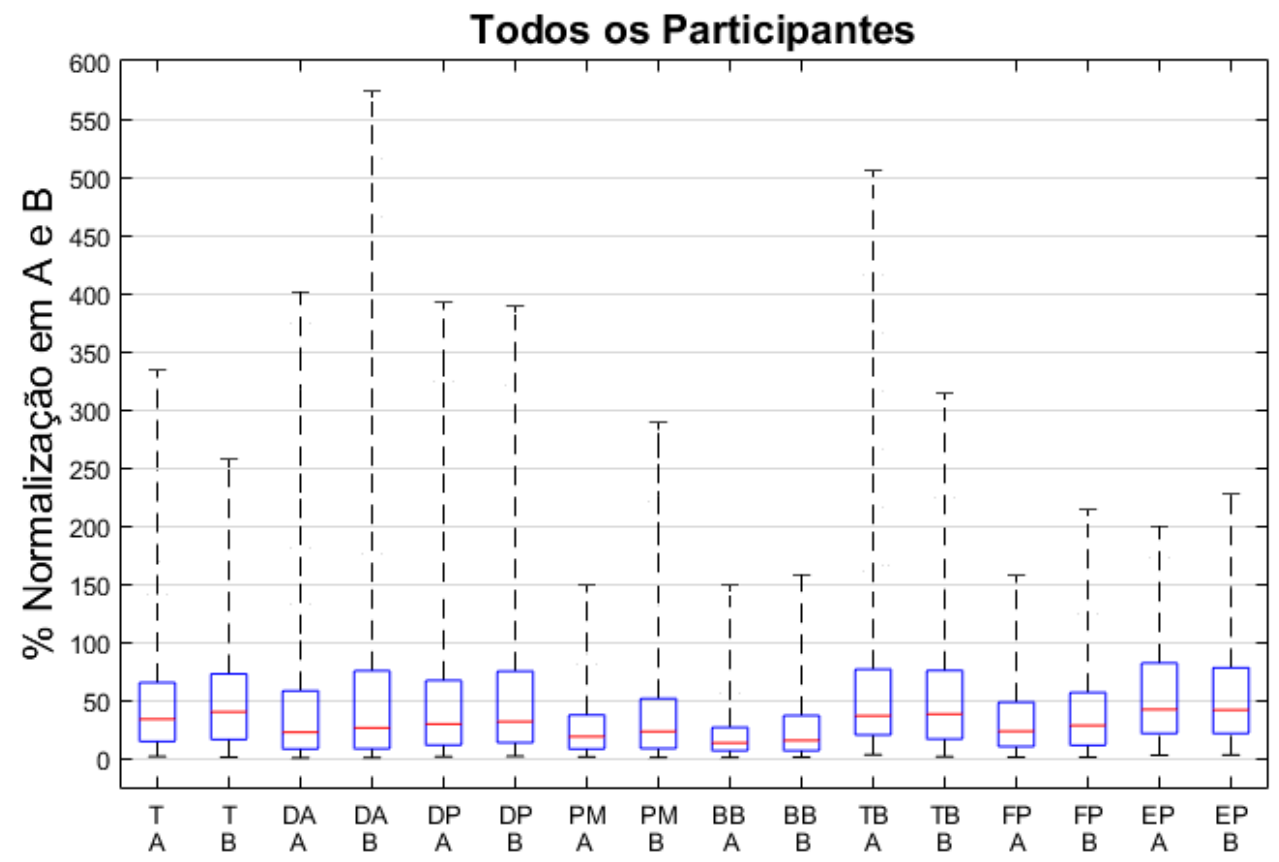

Legenda de siglas, eixo horizontal primeira linha: trapézio superior (T), deltoide anterior (DA), deltoide posterior (DP), peitoral maior (PM), bíceps braquial (BB), tríceps braquial (TB), flexores de punho (FP) e extensores de punho (EP); segunda linha: normalizado na posição $A(A)$ e normalizado na posição $B(B)$. Fonte: Elaborada pelo autor.

Foram calculados os coeficientes de variação intra participantes (CVintra) entre as repetições da propulsão por cada grupo muscular e participante (Tabela 4)(Figura 16). Entre o total de observações ocorrem 3 casos em que os CVintra ultrapassam 30\%, o TB do participante 2, o DP do participante 6 e o DP do participante 11 . No intervalo entre CVintra 25\% e 30\% ocorrem 2 casos, FP do participante 4 e T do participante 10. 
Tabela 4 - Valores calculados do coeficiente de variação intra participantes (CVintra) para cada grupo muscular de cada participante.

\begin{tabular}{|c|c|c|c|c|c|c|c|c|}
\hline \multirow[b]{2}{*}{ Participante } & \multicolumn{8}{|c|}{ CVintra participantes (\%) } \\
\hline & $\mathrm{T}$ & DA & DP & PM & BB & TB & FP & EP \\
\hline 1 & 21,04 & 10,48 & 17,34 & 8,57 & 15,61 & 11,26 & 12,02 & 9,69 \\
\hline 2 & 18,42 & 8,03 & 16,69 & 6,51 & 11,19 & 44,13 & 7,88 & 7,33 \\
\hline 3 & 18,04 & 8,67 & 15,59 & 10,49 & 9,45 & 8,76 & 12,59 & 17,38 \\
\hline 4 & 11,77 & 14,84 & 10,82 & 10,99 & 22,47 & 8,82 & 27,44 & 19,43 \\
\hline 5 & 19,05 & 14,21 & 12,60 & 18,64 & 22,80 & 8,09 & 13,79 & 3,19 \\
\hline 6 & 11,18 & 9,05 & 37,75 & 10,44 & 6,30 & 18,59 & 7,49 & 8,41 \\
\hline 7 & 12,88 & 14,61 & 14,50 & 10,87 & 18,41 & 18,86 & 11,56 & 15,67 \\
\hline 8 & 12,50 & 11,01 & 15,33 & 7,70 & 10,80 & 14,40 & 19,61 & 14,38 \\
\hline 9 & 11,32 & 8,79 & 20,76 & 16,25 & 20,03 & 23,44 & 14,55 & 11,88 \\
\hline 10 & 25,98 & 17,23 & 7,77 & 6,90 & 7,66 & 13,28 & 17,09 & 7,44 \\
\hline 11 & 13,09 & 9,25 & 59,71 & 9,32 & 18,22 & 12,20 & 11,81 & 6,76 \\
\hline
\end{tabular}

Legenda de siglas: trapézio superior (T); deltoide anterior (DA); deltoide posterior (DP); peitoral maior (PM); bíceps braquial (BB); tríceps braquial (TB); flexores de punho (FP); extensores de punho (EP). Fonte: Elaborada pelo autor.

Figura 16 - Representação gráfica dos valores calculados do coeficiente de variação intra participantes (CVintra) agrupados por participante.

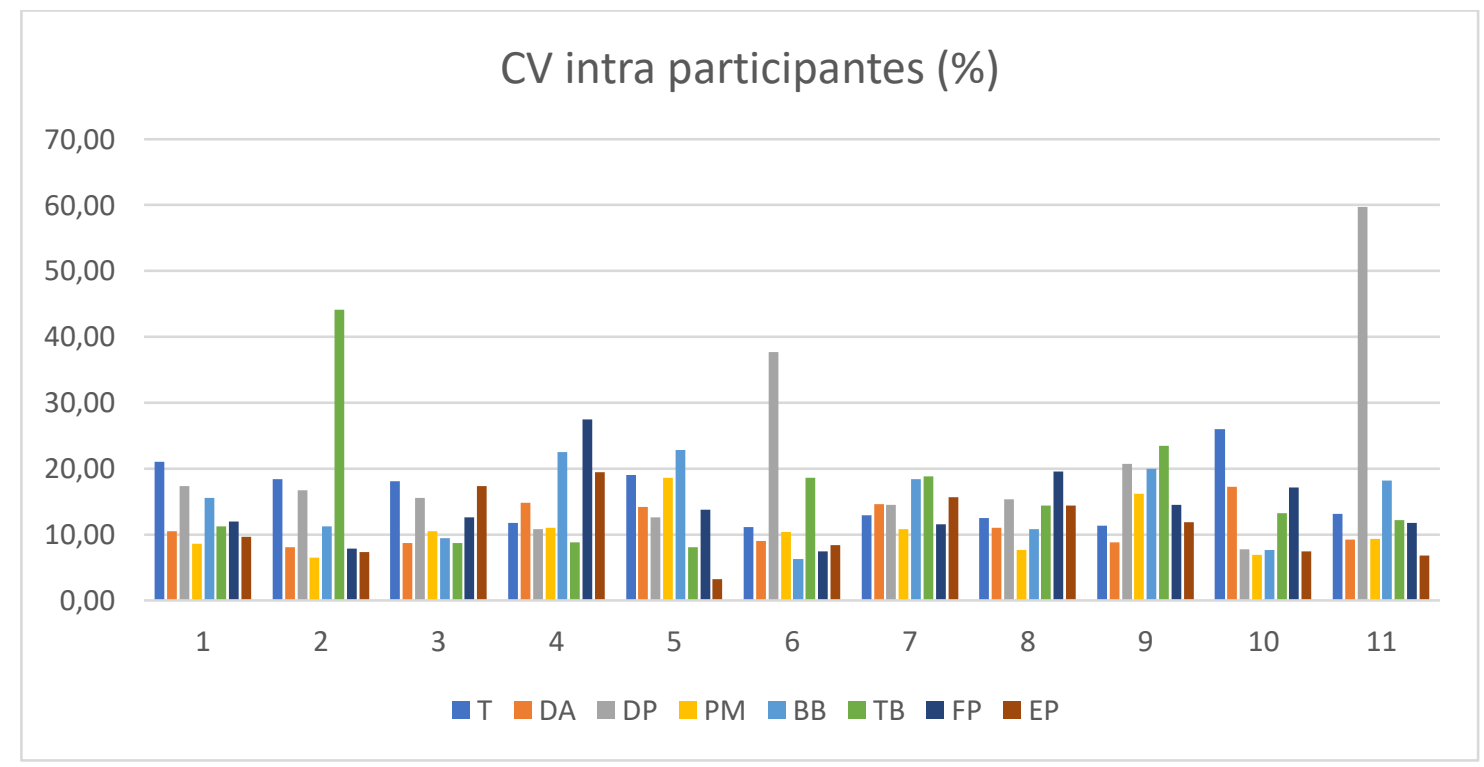

Legenda de siglas: trapézio superior (T); deltoide anterior (DA); deltoide posterior (DP); peitoral maior (PM); bíceps braquial (BB); tríceps braquial (TB); flexores de punho (FP); extensores de punho (EP). Fonte: Elaborada pelo autor.

Os coeficiente de variação inter participantes (CVinter) entre as repetições da propulsão de cada participante por cada grupo muscular constam na Tabela 5 e Figura 17. Entre o total de observações ocorrem 3 casos em que os CVinter ultrapassam 30\%: o TB do participante 2, o DP do participante 6 e o DP do participante 11 . No intervalo entre 
CVintra 25\% e 30\% acontecem 2 vezes: FP do participante 4 e T do participante 10. Os demais valores apresentaram-se abaixo de $25 \%$.

Tabela 5 - Valores calculados do coeficiente de variação inter participantes (CVinter) para cada grupo muscular de cada participante.

\begin{tabular}{|c|c|c|c|c|c|c|c|c|}
\hline \multirow[b]{2}{*}{ Participante } & \multicolumn{8}{|c|}{ CV inter participantes (\%) } \\
\hline & $\mathrm{T}$ & DA & DP & PM & BB & TB & FP & EP \\
\hline 1 & 22,18 & 11,04 & 18,28 & 9,04 & 16,45 & 11,87 & 12,67 & 10,21 \\
\hline 2 & 19,41 & 8,47 & 17,60 & 6,86 & 11,80 & 46,52 & 8,31 & 7,72 \\
\hline 3 & 19,02 & 9,14 & 16,43 & 11,05 & 9,96 & 9,24 & 13,28 & 18,32 \\
\hline 4 & 12,41 & 15,64 & 11,41 & 11,59 & 23,68 & 9,30 & 28,92 & 20,48 \\
\hline 5 & 20,08 & 14,98 & 13,28 & 19,64 & 24,04 & 8,52 & 14,54 & 3,36 \\
\hline 6 & 11,78 & 9,54 & 39,79 & 11,00 & 6,64 & 19,59 & 7,90 & 8,87 \\
\hline 7 & 13,58 & 15,40 & 15,29 & 11,46 & 19,40 & 19,88 & 12,19 & 16,52 \\
\hline 8 & 13,17 & 11,60 & 16,16 & 8,11 & 11,38 & 15,18 & 20,67 & 15,16 \\
\hline 9 & 11,94 & 9,26 & 21,88 & 17,12 & 21,11 & 24,71 & 15,34 & 12,52 \\
\hline 10 & 27,39 & 18,16 & 8,19 & 7,28 & 8,08 & 14,00 & 18,02 & 7,85 \\
\hline 11 & 13,80 & 9,75 & 62,94 & 9,83 & 19,21 & 12,86 & 12,45 & 7,13 \\
\hline
\end{tabular}

Legenda de siglas: trapézio superior (T); deltoide anterior (DA); deltoide posterior (DP); peitoral maior (PM); bíceps braquial (BB); tríceps braquial (TB); flexores de punho (FP); extensores de punho (EP). Fonte: Elaborada pelo autor.

Figura 17 - Representação gráfica dos valores calculados do coeficiente de variação inter participantes (CVinter) agrupados por grupo muscular.

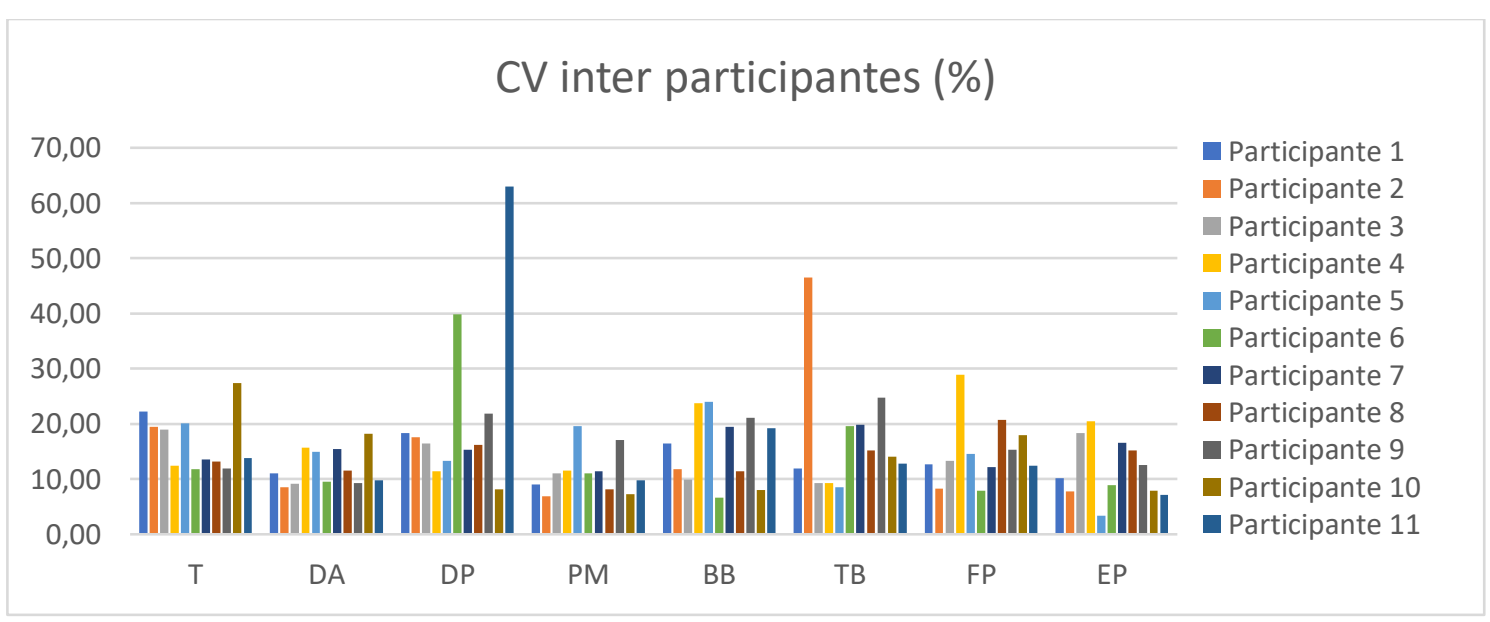

Legenda de siglas: trapézio superior $(T)$; deltoide anterior (DA); deltoide posterior (DP); peitoral maior (PM); bíceps braquial (BB); tríceps braquial (TB); flexores de punho (FP); extensores de punho (EP). Fonte: Elaborada pelo autor. 


\subsection{Perfil da ativação muscular ao longo de uma propulsão: resultados}

Nesta seção, apresenta-se a segunda forma para identificar as características de ativação muscular durante a execução do gesto de propulsão. Aqui os resultados são retratados nas Figuras 18 à 25, de forma a permitir uma análise exploratória. Com base nessa metodologia de normalização, observa-se que os grupos musculares que atingem os maiores picos de ativação na propulsão são DA (80,27\%), PM (79,27\%), FP (78,93\%) e EP (80,65\%). Em relação a estes, os grupos musculares T (69,49\%), DP (69,85\%), BB (70,34\%), TB (70,58\%) apresentam picos ativação menores.

Figura 18 - Ativação muscular do trapézio superior (T) normalizado pelo pico dinâmico e normalizado pelo ciclo de uma propulsão.

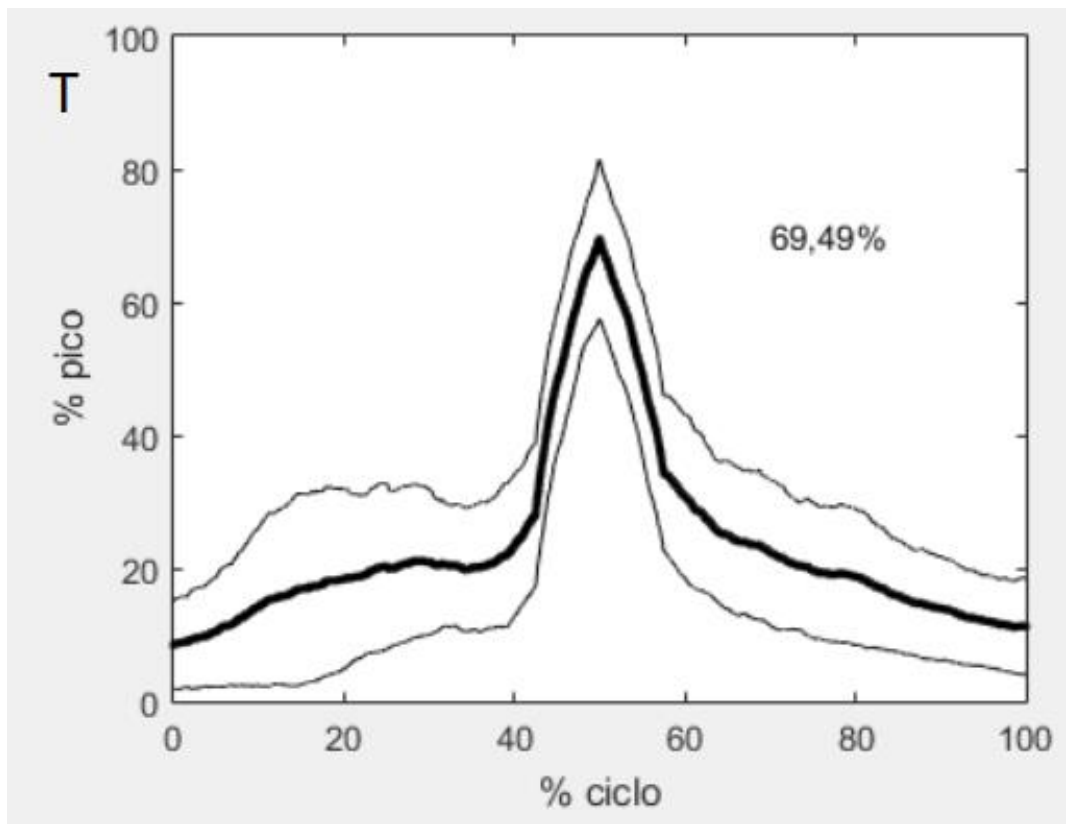

Legenda: A curva central em negrito representa os valores médios enquanto as curvas superior e inferior representam o intervalo de um desvio padrão. O valor expresso acima das curvas corresponde ao nível do pico de ativação muscular.

Fonte: Elaborado pelo autor. 
Figura 19 - Ativação muscular do deltóide anterior (DA) normalizado pelo pico dinâmico e normalizado pelo ciclo de uma propulsão.

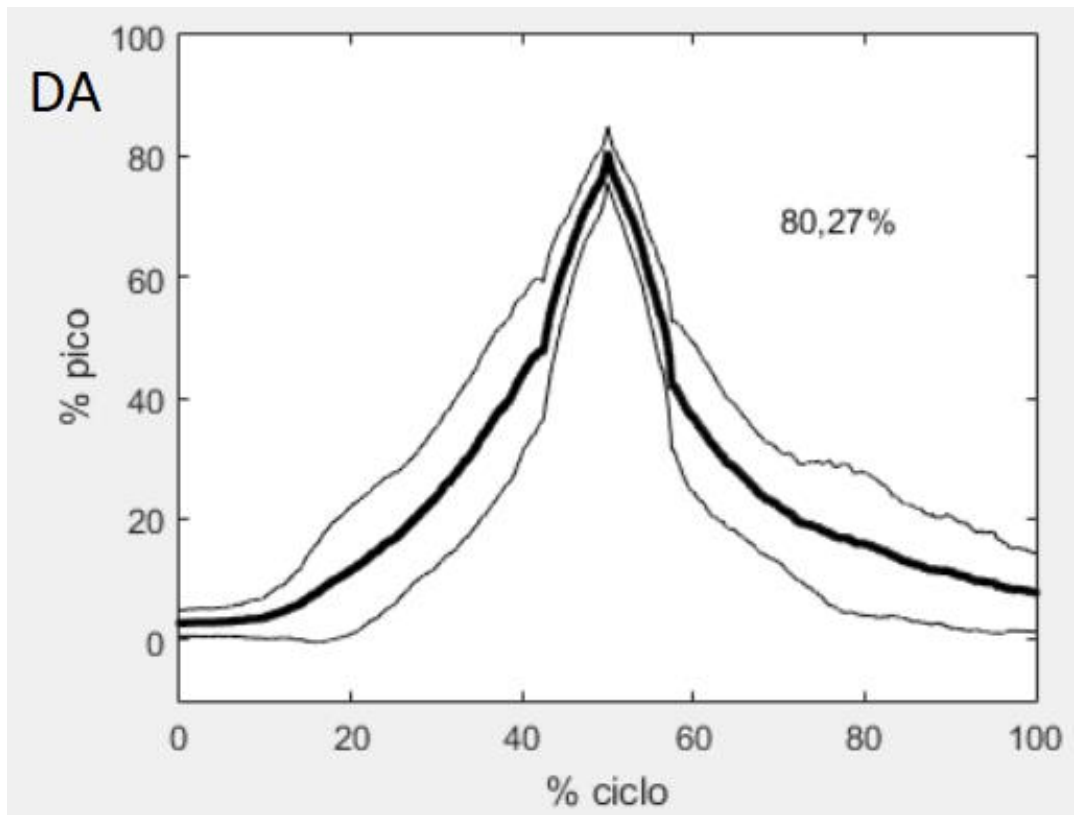

Legenda: A curva central em negrito representa os valores médios enquanto as curvas superior e inferior representam o intervalo de um desvio padrão. O valor expresso acima das curvas corresponde ao nível do pico de ativação muscular.

Fonte: Elaborada pelo autor.

Figura 20 - Ativação muscular do deltoide posterior (DP) normalizado pelo pico dinâmico e normalizado pelo ciclo de uma propulsão.

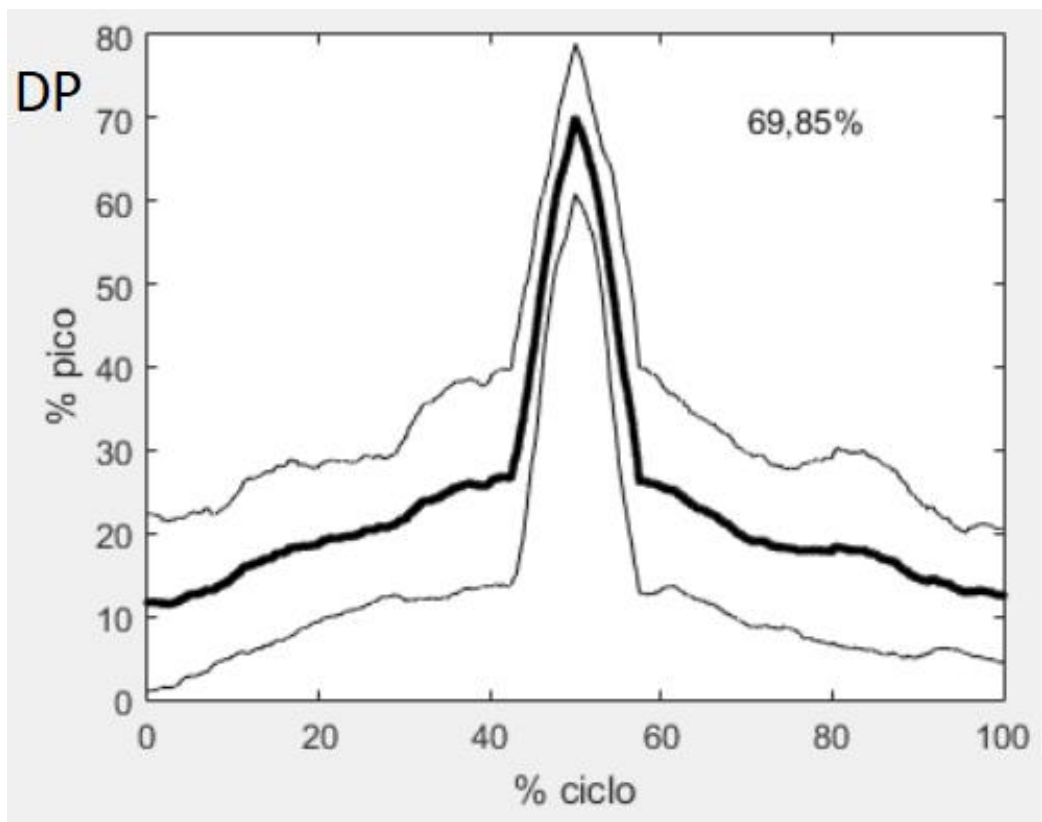

Legenda: A curva central em negrito representa os valores médios enquanto as curvas superior e inferior representam o intervalo de um desvio padrão. O valor expresso acima das curvas corresponde ao nível do pico de ativação muscular.

Fonte: Elaborada pelo autor. 
Figura 21 - Ativação muscular do peitoral maior (PM) normalizado pelo pico dinâmico e normalizado pelo ciclo de uma propulsão.

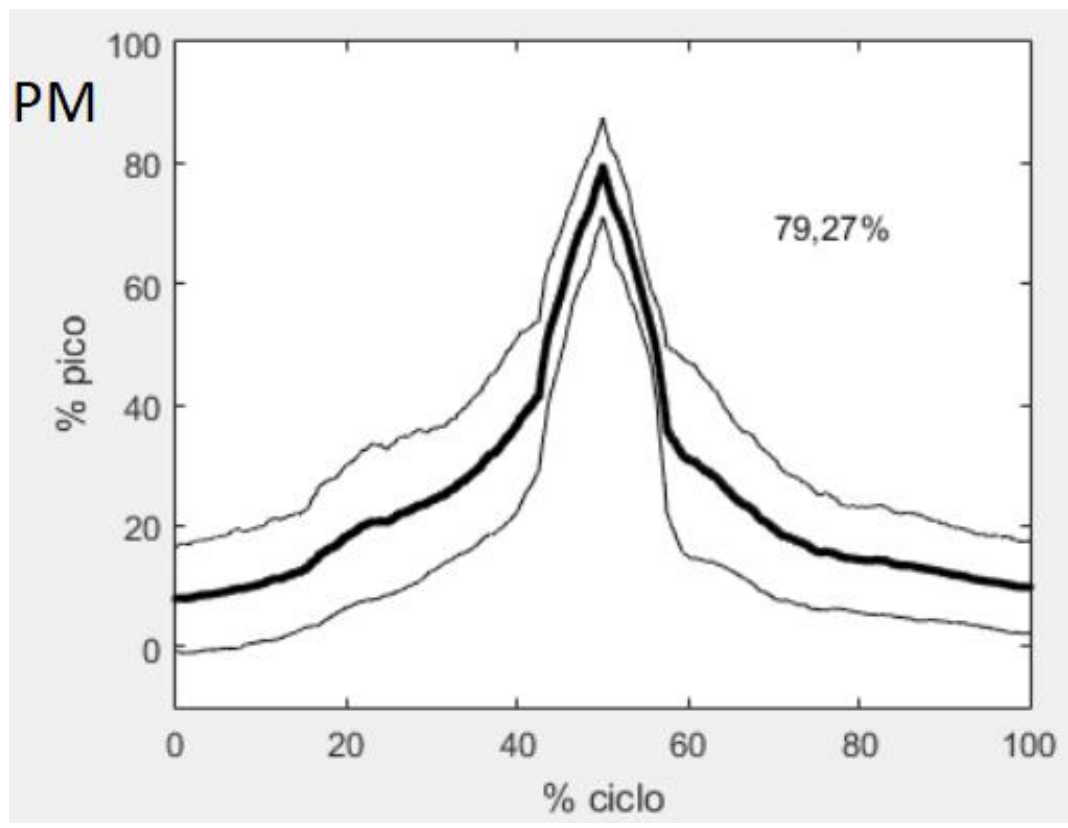

Legenda: A curva central em negrito representa os valores médios enquanto as curvas superior e inferior representam o intervalo de um desvio padrão. O valor expresso acima das curvas corresponde ao nível do pico de ativação muscular.

Fonte: Elaborada pelo autor.

Figura 22 - Ativação muscular do bíceps braquial (BB) normalizado pelo pico dinâmico e normalizado pelo ciclo de uma propulsão.

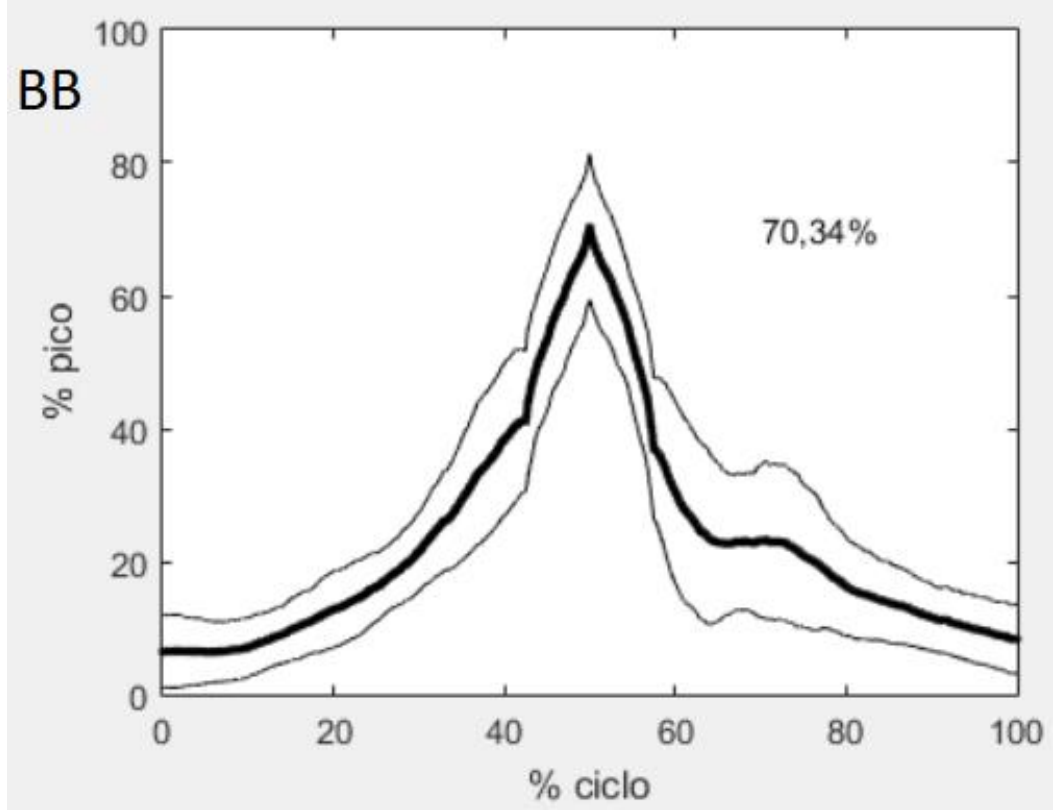

Legenda: A curva central em negrito representa os valores médios enquanto as curvas superior e inferior representam o intervalo de um desvio padrão. O valor expresso acima das curvas corresponde ao nível do pico de ativação muscular.

Fonte: Elaborada pelo autor. 
Figura 23 - Ativação muscular do tríceps braquial (TB) normalizado pelo pico dinâmico e normalizado pelo ciclo de uma propulsão.

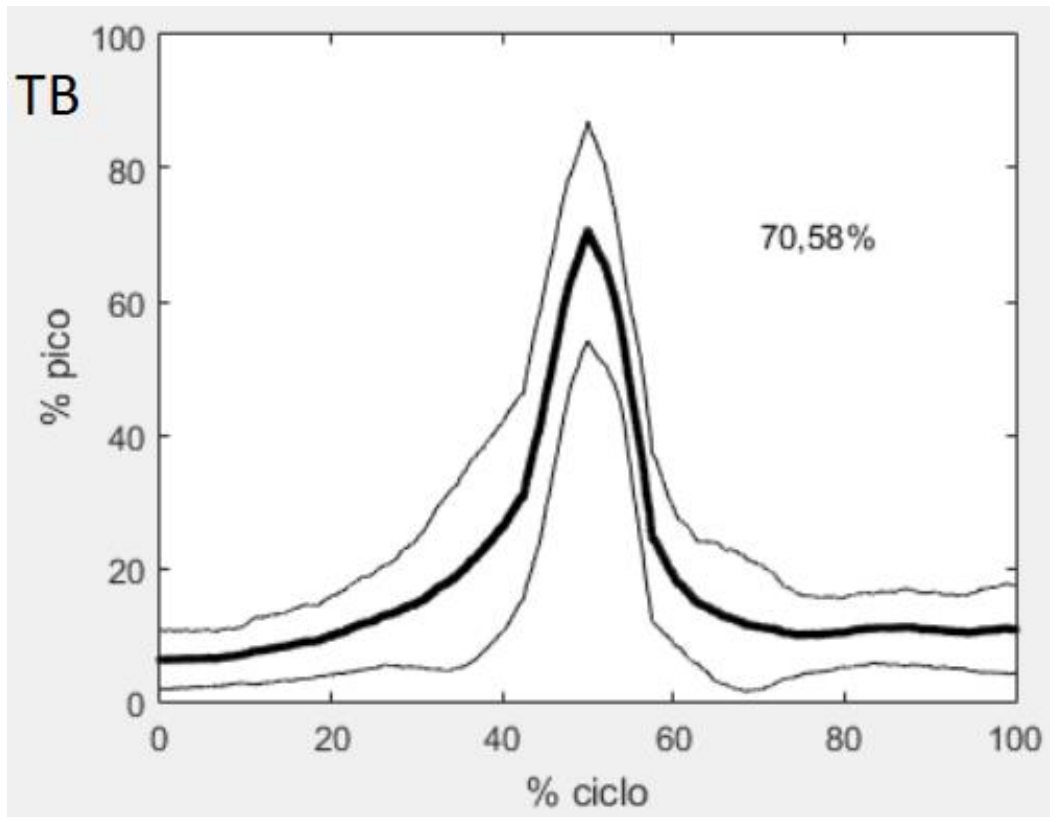

Legenda: A curva central em negrito representa os valores médios enquanto as curvas superior e inferior representam o intervalo de um desvio padrão. O valor expresso acima das curvas corresponde ao nível do pico de ativação muscular.

Fonte: Elaborada pelo autor.

Figura 24 - Ativação muscular dos flexores de punho (FP) normalizado pelo pico dinâmico e normalizado pelo ciclo de uma propulsão.

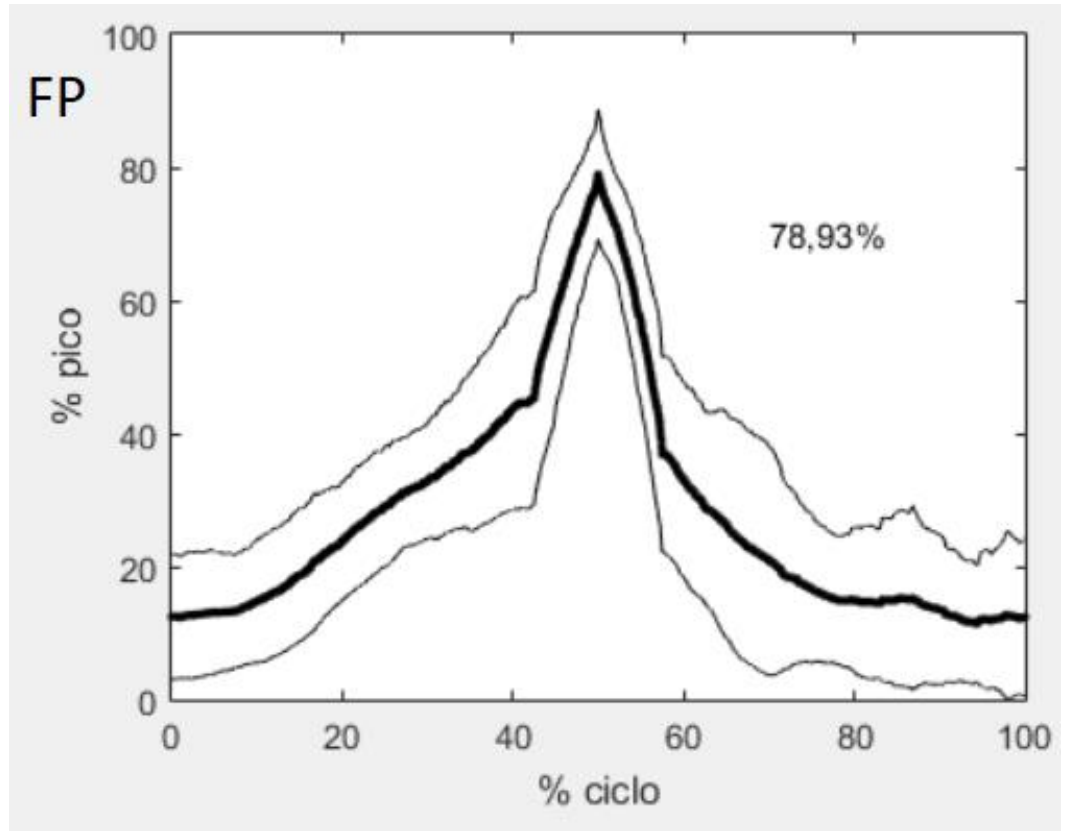

Legenda: A curva central em negrito representa os valores médios enquanto as curvas superior e inferior representam o intervalo de um desvio padrão. O valor expresso acima das curvas corresponde ao nível do pico de ativação muscular.

Fonte: Elaborada pelo autor. 
Figura 25 - Ativação muscular dos extensores de punho (EP) normalizado pelo pico dinâmico e normalizado pelo ciclo de uma propulsão.

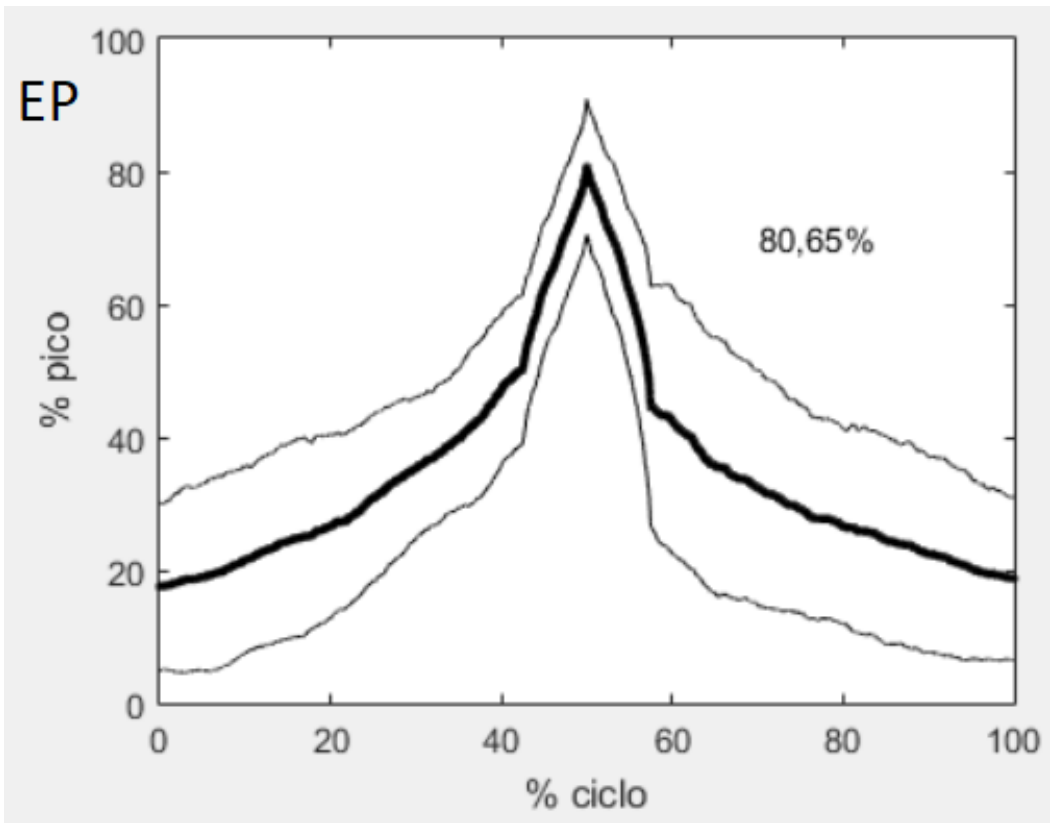

Legenda: A curva central em negrito representa os valores médios enquanto as curvas superior e inferior representam o intervalo de um desvio padrão. $O$ valor expresso acima das curvas corresponde ao nível do pico de ativação muscular.

Fonte: Elaborada pelo autor.

Também foram calculados os coeficiente de variação inter participantes por grupo muscular (Tabela 6)(Figura 26). Estes representam o coeficiente de variação inter participantes (CVinter) juntando o total de observações de todos os participantes a cerca do mesmo grupo muscular. Verifica-se que em todos os grupos musculares, os CVinter normalizados em A são menores em relação aos normalizados em B. As maiores diferenças encontram-se nos grupos musculares PM, DA e BB com respectivamente, $46,29 \%, 19,78 \%$ e $18,79 \%$. Entre os normalizados A, apresentam-se DA, DP e T com os maiores resultados, enquanto PA, DM e DP os maiores em B. 
Tabela 6 - Valores calculados do coeficiente de variação inter participantes (CVinter) por grupo muscular do total da amostra.

\begin{tabular}{lll}
\hline & \multicolumn{2}{l}{ CV inter participantes (\%) } \\
& A & B \\
\hline T & 62,16 & 62,96 \\
DA & 67,79 & 87,57 \\
DP & 65,71 & 70,24 \\
PM & 36,94 & 83,22 \\
BB & 46,27 & 65,07 \\
TB & 56,53 & 57,68 \\
FP & 31,07 & 37,69 \\
EP & 41,25 & 48,94 \\
\hline
\end{tabular}

Legenda de siglas: trapézio superior (T); deltoide anterior (DA); deltoide posterior (DP); peitoral maior (PM); bíceps braquial (BB); tríceps braquial (TB); flexores de punho (FP); extensores de punho (EP). Fonte: Elaborada pelo autor.

Figura 26 - Representação gráfica dos valores calculados do coeficiente de variação inter participantes (CVinter) agrupados por grupo muscular do total da amostra.

\section{CV inter participantes (\%)}

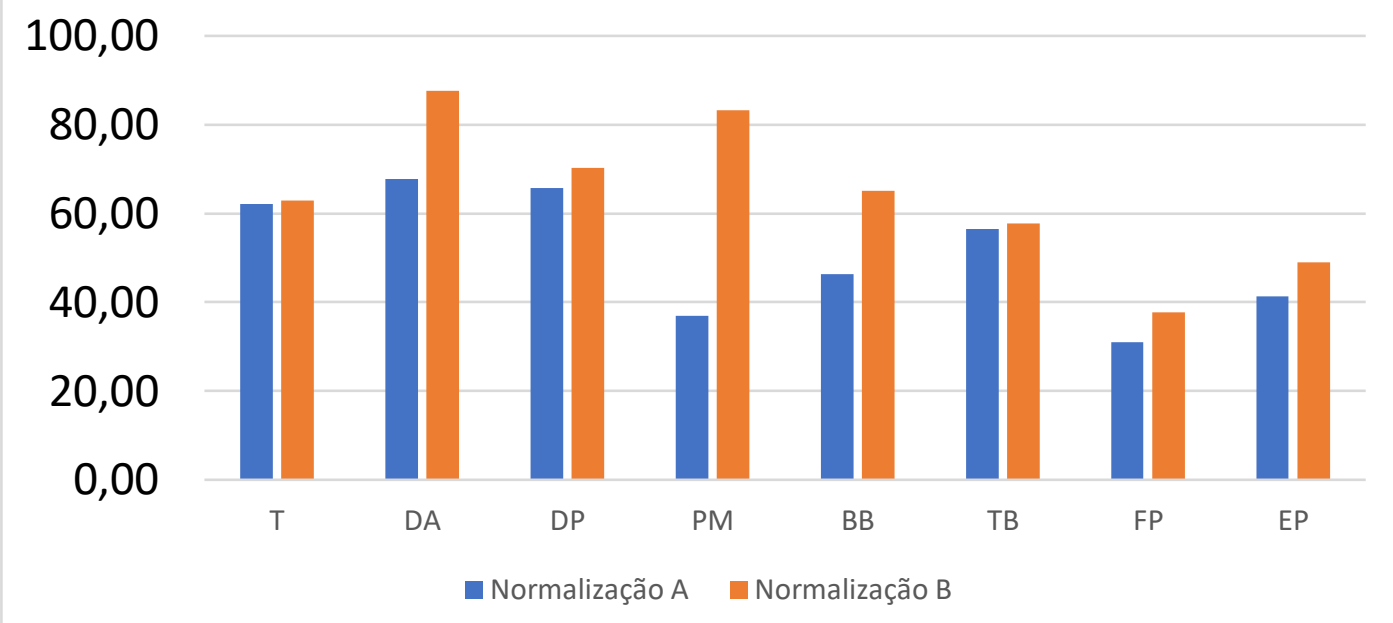

Legenda de siglas: trapézio superior (T); deltoide anterior (DA); deltoide posterior (DP); peitoral maior (PM); bíceps braquial (BB); tríceps braquial (TB); flexores de punho (FP); extensores de punho (EP). Fonte: Elaborada pelo autor. 


\section{Discussão}

Este estudo possui natureza descritiva, sendo o objetivo descrever as ativações musculares em músculos do tronco, braço e antebraço durante a fase de impulsão inicial da autopropulsão de cadeira de rodas. Para tanto, através da eletromiografia, foram propostas duas formas de apresentação. A primeira diz a respeito dos níveis de ativação atingidos pelos grupos musculares envolvidos no gesto da autopropulsão. A segunda visa revelar um perfil do acionamento muscular ao longo da excursão do gesto objeto do estudo.

Em relação a primeira estratégia foi apresentado um modo diferente de se normalizar os dados eletromiográficos da autopropulsão da cadeira rodas. Esta normalização deriva-se do método de referenciar a partir do teste de esforço da contração isométrica voluntária máxima (CIVM). A diferença consiste na posição corporal ao realizar o teste. Enquanto outros testes propostos (BOETTCHER; GINN; CATHERS, 2008; CRAM; KASMAN; HOLTZ, 1998; KELLY et al., 1996; NIEMINEN; TAKALA; VIIKARI-JUNTURA, 1993; WESTGAARD, 1988) seguem posições anatômicas específicas, posicionando segmentos em 90 graus e adquirindo-se um grupo muscular de cada vez, o modelo proposto realiza a coleta de todos os grupos musculares simultaneamente na própria postura empenhada ao propulsionar a cadeira de rodas. A intenção da postura selecionada no presente método de normalização seria para além de aproximar-se ao gesto estudado, conferir uma percepção relativa de esforço frente a um possível máximo que o corpo poderia empregar em solicitação mecânica total do próprio movimento. Dentro deste propósito, definiu-se 2 posições entre as possibilidades compreendidas no decorrer do gesto de propulsão: A (30 graus posterior ao topo do aro de propulsão) e B (no topo do aro).

Como apresentado nas Figuras 4 à 15, os níveis do pico de ativação em vários momentos ultrapassaram o 100\%. A hipótese que se levanta frente a este fato é de que para cada trecho da trajetória do gesto de autopropulsão, existem pontos no aro de propulsão que demandam diferentes acionamentos musculares devido a variadas conformações mecânicas assumidas ao longo do movimento. Assim, valores de ativação muscular que superaram o $100 \%$, sugerem que no decurso do gesto da propulsão, atingiram valores maiores em relação aos requisitados nos pontos de normalização: 
posição A e posição B (Figura 3)(VANLANDEWIJCK; THEISEN; DALY, 2001). Pode-se observar que dependendo do local adotado para normalização, os mesmos dados assumem magnitudes diferentes comparadas entre si. Também pode se verificar que de um participante para outro, não seguem o mesmo padrão de proporção entre os valores normalizados em A e em B. Mesmo quando comparados entre o mesmo grupo muscular. Para exemplificar, cita-se a condição do DA. Neste grupo muscular, num total dos 11 participantes, foram observados 6 participantes que atingiram picos de ativação normalizados em $A$ maiores que os normalizados em $B$, sendo que os outros 5 participantes apresentaram os níveis de pico de ativação do DA maiores em B. Isso acontece pois não apenas a posição da trajetória manual no aro define o resultado das variadas conformações posturais. Diversos fatores influenciam nessa distribuição como diferenças no ajuste das cadeiras rodas (BONINGER et al., 2002; COWAN et al., 2009; MEDOLA et al., 2014), nas resistências de rolamentos (BASCOU et al., 2013, KWARCIAK et al., 2009; VAN DER WOUDE et al., 2003), posicionamentos do eixo da roda traseira (BERTOLACCINI et al., 2017; BONINGER et al., 2000; KOTAJARVI et al., 2004), nas características de cada lesão medular (BEEKMAN; MILLER-PORTER; SCHONEBERGER, 1999; DELLABIANCIA; PORCELLINI; MEROLLA, 2013; QI et al., 2012; REQUEJO, 2008), na velocidade do deslocamento do sistema usuário-cadeira de rodas (WALTER; CONANT, 1974) e das próprias diferenças intrínsecas entre indivíduos (HARBURN; SPAULDING, 1986).

Uma possibilidade para isentar parcialmente essas diferenças seria usar uma mesma cadeira de rodas para todos os participantes. Entretanto, uma única cadeira de rodas não estaria ajustada proporcionalmente as dimensões antropométricas individuais. Outra questão influenciadora quanto aos resultados diferentes entre as demandas musculares, refere-se a impulso do tronco (YANG et al., 2006). Durante o experimento não foram fornecidas instruções quanto à utilização do tronco. Esta apresentou-se uma limitação do estudo reconhecida previamente às coletas de dados. Isso porque ao definir-se o uso da própria cadeira de rodas de cada participante constatou-se que em várias delas não haviam as rodas anti tombos traseira, de modo que se não aproveitassem o balanço do tronco, ou se fossem fixados ao encosto, ocasionariam em queda. Esta condição também foi intensificada devido ao protocolo de 
propulsão delineado no experimento ser de máxima impulsão possível exercida pelo participante.

Com relação ao protocolo de impulsão máxima, sua escolha se deu com intuito de retratar a propulsão inicial numa situação de estresse mecânico máximo, além de propiciar uma conveniência na normalização utilizada na segunda proposta metodológica deste estudo. Visando expor os dados das ativações musculares, optouse por representá-lo na forma de gráficos boxplot. Desta maneira entende-se adequada o formato apresentado dado que assim não ocorre perdas de informação expondo somente valores centrais das ativações (medianas) ou apenas os picos de ativação. Sobre as medianas pode-se ter uma percepção do tempo de trabalho intenso. Quanto mais altos os valores das medianas, indica um acionamento de determinado musculo mais intenso mantendo valores elevados por mais tempo durante o gesto.

Por causa das limitações do modelo de normalização na proposta primeira das ativações musculares, prejudicou-se a interpretação dos dados quanto aos níveis de ativação muscular pico. Uma sugestão para contornar o problema do trecho de coleta de normalização, seria aplicar o procedimento do teste CIVM em vários locais do arco da trajetória da propulsão. Mediante a isso, definiria-se os pontos que apresentassem as maiores ativações para cada grupo muscular como o seu respectivo ponto de normalização e replicando o mesmo arranjo para todos os participantes. Outra sugestão de solução interessante seria a aplicação da coleta de normalização numa contração isocinética. Esta solução eliminaria o problema de se normalizar uma contração dinâmica, como a propulsão, em uma contração isométrica que guarda pouca relação com a contração dinâmica. Além de que, nesta proposta de sugestão isocinética, teriase os dados referenciados numa trajetória arco completa da propulsão executada em esforço máximo dinâmico.

Também foram calculados os coeficientes de variação intra participantes (CVintra) e inter participantes (CVinter). Os motivos de selecionar estas medidas foram para facilitar a interpretação dos dados em detrimento da escolha de um instrumento estatístico mais complexo. Os valores de CVintra baixos representam consistência de um participante entre repetidas medidas da propulsão. Na figura 16 estão agrupados os CVintra dos 8 grupos musculares avaliados por participante. Destaques são notados em 3 situações em que os valores superam os $30 \%$, apontando um erro elevado e baixa 
consistência entre as repetições das propulsões: TB do participante 2 (44,13\%), DP do participante $6(37,75 \%)$ e DP do participante 11 (59,71\%). Pensando em um experimento que pesquisa os efeitos dos ajustes da cadeira de rodas do ponto de vista do acionamento muscular, o CVintra pode ser usado como uma opção para se quantificar o erro. Neste exemplo, seria comparado as propulsões de um mesmo participantes entre CR com uma determinada dimensão alterada, exprimindo a influência deste ajuste no recrutamento muscular. Devido a limitação do uso das CR do próprio participante, este estudo para se acrescentar mais este objetivo, seria necessária uma CR com um sistema ajustável ou pelo menos mais de uma CR semelhantes com diferenças pontuais.

Tratando-se de uma medida de variabilidade relativa, foi calculado os coeficientes de variação inter participantes (CVinter), permitindo-se uma comparação das variações entre participantes. Um alto CVinter indica uma grande dispersão dos dados. Em outras palavras significa uma curva de propulsão com trechos não bem definidos de ascensão e declínio. Na figura 17, agrupou-se os valores de CVinter por grupo muscular promovendo uma comparação entre os grupos musculares dos participantes. Os dados de maneira geral encontram-se entre o intervalo $3 \%$ a $20 \%$. Valores de CVinter próximo de zero não são tão desejáveis pois significam uma variação muito baixa das repetidas propulsões indicando uma homogeneidade excessiva da amostra. Por outro lado, valores muito altos mostram uma variabilidade muito grande e sugerem uma quantidade maior de repetições para se encontrar padrões a fim de compararmos os resultados com outras situações. No caso de experimentos que visem a construção de padrões de técnica de movimento e suas repercussões nas respostas eletromiográficas, o CVinter poderia ser empregado para representar o erro. Neste exemplo, seria comparada as propulsões entre participantes com dimensões antropométricas semelhantes utilizando a mesma cadeira de rodas ou, ao menos, entre participantes que utilizassem CR ajustadas proporcionalmente iguais, seguindo as mesmas diretrizes e protocolo de ajuste. Situação esta que não ocorreu neste estudo. Além de que, para acrescentar isto aos objetivos, também seria necessário o registro das trajetórias espaciais dos segmentos corporais já que com apenas os dados eletromiográficos não é possível estabelecer tal análise. Principalmente pelo fato de que boa parte das análises sobre técnicas de movimento de propulsão de CR envolvem a fase de recuperação, sendo que neste estudo concentrou-se apenas a fase de tração, 
posto que o enfoque relaciona-se ao período subsequente a interrupção da inércia de repouso.

Sobre a segunda metodologia escolhida para apresentar os dados e identificar as ativações musculares no movimento da autopropulsão da cadeira de rodas, consiste em expor gráficos, exibindo um perfil de ativação muscular ao longo da execução do gesto da autopropulsão na cadeira de rodas. Nesse método os dados foram normalizados em relação ao pico dinâmico da própria tarefa correspondente ao mesmo participante e grupo muscular. Também foi normalizado quanto ao período de um ciclo de propulsão desejando-se agrupar os dados formando uma representação única do perfil de ativação.

Dado que o protocolo definido para execução das propulsões foi em esforço máximo, a utilização da normalização através do pico dinâmico torna-se conveniente, pois os dados são normalizados em uma mesma especificidade de contração dinâmica. Neste caso os resultados apresentados na ativação pico guardam uma relação maior com a natureza do gesto em relação a primeira proposta. No entanto por consequência de não ter outro método de coleta de dados, sincronizado com a aquisição dos dados eletromiográficos que referenciassem o início e o fim do deslocamento, foi preciso estabelecer um critério para definição do início do ciclo de propulsão. Com base em um critério matemático, este ponto foi calculado a partir do período de pré carga, trecho anterior ao início da propulsão, elegendo o primeiro ponto na sequencia de dados que ultrapassasse a média mais 3 desvios padrões dos dados encontrados no período de pré carga. Esse método aparentemente funcionou bem para a definição do início, já que no período de pré carga o participante ficava apenas sustentando a postura pré autopropulsão com as mãos nos aros das rodas. A discrepância dos dados nessa condição, frente a condição em propulsão, viabilizou dentro de uma baixa margem de erro no tempo o ponto crítico, considerado como início do movimento. No entanto, por mais que os participantes tenham cumprido a instrução após propulsão (depois do abandono das mãos ao aro das rodas) de não movimentarem os braços e soltarem completamente sobre as pernas, o sinal eletromiográfico na maioria dos casos não se comportou similarmente ao período de pré carga. Foi notada uma variação significante dos dados coletados relativo as magnitudes do trecho alvo do estudo. Com isso, a definição do ponto estabelecido como fim do ciclo de propulsão, 
possui um erro na margem do tempo maior. Infelizmente, também em consequência de não haver um outro método sincronizado que sinalizasse início e fim do deslocamento, não foi possível quantificar os erros temporais de início e fim do critério estabelecido.

Estudos prévios que investigaram a propulsão de cadeira de rodas através da eletromiografia utilizaram métodos diferentes para definição de início e fim do ciclo considerado como propulsão. Chow et al. (2009) e Gagnon et al. (2015) sincronizaram os dados eletromiográficos com a aquisição de dados cinemáticos. Já Mulroy et al. (2004), Qi et al. (2012) e Yang et al. (2006), utilizaram-se de sincronização com a aquisição de dados cinéticos. Outros estudos envolvendo eletromiografia e propulsão da cadeira de rodas que não necessitaram de outra metodologia como suporte, não tiveram a necessidade de definir-se início e fim do ciclo de propulsão como no experimento de Harburn e Spaulding (1986).

Considerações feitas, os resultados apresentados nas Figuras 18 à 25 fornecem informações a partir de uma análise exploratória do comportamento eletromiográfico durante o curso do gesto de propulsão. Apesar das limitações encontradas no início e fim das curvas, pode-se ter uma interpretação quando os níveis percorridos no trecho central, na fase de ascensão da curva e na fase de declínio. Quanto aos valores de pico de ativação, por meio desta metodologia pode-se observar que entre os 8 grupos musculares avaliados neste estudo, apresentam-se como os mais solicitados: DA (80,27\%), PM (79,27\%), FP (78,93\%) e EP (80,65\%). Estes achados confirmam com Veeger, Van Der Woude e Rozendal (1991), de que os principais músculos efetores na propulsão são o DA e o PM. Os músculos flexores e extensores do punho não foram avaliados na ocasião. Estes sugerem uma ativação alta devido a uma necessidade de estabilizar-se o punho para transferir a produção de força gerada nas articulações mais proximais (KOONTZ; BONINGER, 2003). Estes achados colaboram com altas ocorrências de dores associadas a ombros e punhos entre UCR manuais. O uso prolongado de CR manual os torna propensos a desenvolvimento de lesões. Prescrições de treinamento e programas de atividades físicas voltados para este público devem assumir como foco principal o cuidado e a preparação dos membros superiores. Sobretudo aos grupos musculares deltóide anterior e peitoral maior, uma vez que estes são os mais engajados na propulsão da CR. 
Em virtude de possuir natureza descritiva, este estudo apresentou a propulsão da CR manual em situação inerente ao início do deslocamento e preocupou-se em introduzir um método de normalização específico no estudo de propulsão da CR manual. Assim caracterizando-se como uma etapa anterior, precedente a estudos voltados por exemplo, a explicar os mecanismos e prevenções de lesões referente à propulsão inicial e ações que desenvolvam aprimoramentos da técnica e mobilidade dos UCR. Ainda se faz necessário desenvolvimento de novas metodologias para maiores investigações objetivando avaliar aspectos importantes pertinentes ao gesto de propulsão da CR manual, como o perfil de ativação dos músculos do manguito rotador, assim como qual o ritmo escapular para ótima performance do gesto de propulsão. 


\section{Conclusões}

O objetivo do estudo foi descrever o gesto da fase inicial da autopropulsão de cadeira de rodas manual de UCR, por meio da eletromiografia. Para descrever este movimento, foi adquirido os sinais eletromiográficos de 8 grupos musculares: trapézio superior (T), deltoide anterior (DA), deltoide posterior (DP), peitoral maior (PM), bíceps braquial (BB), tríceps braquial (TB), flexores de punho (FP) e extensores de punho (EP), expondo seus níveis de ativação e comportamento do seu acionamento no tempo no decorrer do movimento. Entre os procedimentos de análise dos dados eletromiográficos, utilizou-se um método alternativo de normalização e uma segunda proposta de normalização, já conhecida como normalização pelo pico dinâmico e com base relativa no tempo de um ciclo do movimento de autopropulsão.

Em ambas as propostas apresentaram limitações diferentes que acabam afetando a interpretação dos resultados. Na primeira proposta a interferência se dá pelo valor utilizado de normalização, que não exprime uma fração possível para interpretar o acionamento muscular em relação a um potencial máximo desempenhado pelo usuário da cadeira de rodas. Na segunda proposta a limitação aconteceu devido a ausência de outro método de aquisição de dados para indicar o início e fim do ciclo de propulsão do participante. Isso porque foi utilizado apenas a eletromiografia e o critério matemático, sendo que este mostrou-se com baixa eficiência na definição do intervalo do ciclo.

Segundo os dados apresentados, entre os 8 grupos musculares, os mais engajados do ponto de vista do acionamento muscular são o deltoide anterior (80,27\%), o peitoral maior $(79,27 \%)$, os flexores de punho $(78,93 \%)$ e os extensores de punho (80,65\%). Estes achados de DA e PM colaboram com Veeger, Van der Woude e Rozendal (1991), os quais concluíram que estes são os músculos principais no gesto de propulsão da CR. 


\section{Sugestões para trabalhos futuros}

Pensando-se na primeira proposta, a fim de melhorar este método de normalização, para sinais eletromiográficos da propulsão de cadeira de rodas, seria interessante realizar a aquisição de mais pontos no aro pelo teste de CIVM mapeando em quais locais apresentam-se um candidato a referência com maiores magnitudes do sinal comparado com as de cada músculo avaliado.

Outra sugestão, ainda sobre esta proposta metodológica, seria a utilização de uma coleta de contração isocinética em esforço máximo. Neste caso os dados de normalização seriam referenciados não por um valor único mas pela curva produzida nas aquisições durante o teste em esforço máximo isocinético. 


\section{Referências}

ARNET, U. et al. Force application during handcycling and handrim wheelchair propulsion: an initial comparison. Journal Of Applied Biomechanics, v.29, n.6, p.687695, Dec. 2013. Doi: http://dx.doi.org/10.1123/jab.29.6.687.

BASCOU, J. et al. A Method for the field assessment of rolling resistance properties of manual wheelchairs. Computer Methods In Biomechanics And Biomedical Engineering, v.16, n.4, p.381-391, Apr. 2013. Doi: http://dx.doi.org/10.1080/10255842.2011.623673.

BEEKMAN, C.; MILLER-PORTER, L.; SCHONEBERGER, M. Energy cost of propulsion in standard and ultralight wheelchairs in people with spinal cord injuries. Physical Therapy, v.79, n.2, p.146-158, Feb. 1999. Doi: http://dx.doi.org/10.1093/ptj/79.2.146.

BERTOLACCINI, G.S. et al. The Influence of axle position and the use of accessories on the activity of upper limb muscles during manual wheelchair propulsion. International Journal Of Occupational Safety And Ergonomics, 2017. Doi: http://dx.doi.org/10.1080/10803548.2017.1294369.

BOETTCHER, C.E.; GINN, K.A.; CATHERS, I. Standard maximum isometric voluntary contraction tests for normalizing shoulder muscle EMG. Journal Of Orthopaedic Research, v.26, n.12, p.1591-1597, Dec. 2008. Doi: http://dx.doi.org/10.1002/jor.20675.

BONINGER, M.L. et al. Manual wheelchair pushrim biomechanics and axle position. Archives Of Physical Medicine And Rehabilitation, v.81, n.5, p.608-613, May 2000. Doi: http://dx.doi.org/10.1053/mr.2000.1455.

. Propulsion patterns and pushrim biomechanics in manual wheelchair propulsion. Archives Of Physical Medicine And Rehabilitation, v.83, n.5, p.718-723, May 2002. Doi: http://dx.doi.org/10.1053/apmr.2002.32455.

Shoulder magnetic resonance imaging abnormalities, wheelchair propulsion, and gender11No commercial party having a direct financial interest in the results of the research supporting this article has or will confer a benefit upon the authors(s) or upon any organization with which the author(s) is/are associated. Archives Of Physical Medicine And Rehabilitation, v.84, n.11, p.1615-1620, Nov. 2003. Doi: http://dx.doi.org/10.1053/s0003-9993(03)00282-x.

BURDEN, A.; BARTLETT, R. Normalisation of EMG amplitude: an evaluation and comparison of old and new methods. Medical Engineering \& Physics, v. 21, n. 4, p.247-257, maio 1999. Doi: http://dx.doi.org/10.1016/s1350-4533(99)00054-5.

CHOW, J.W. et al. Kinematic and electromyographic analysis of wheelchair propulsion on ramps of different slopes for young men with paraplegia. Archives Of Physical 
Medicine And Rehabilitation, v.90, n.2, p.271-278, Feb. 2009. Doi: http://dx.doi.org/10.1016/j.apmr.2008.07.019.

COWAN, R.E. et al. Impact of surface type, wheelchair weight, and axle position on wheelchair propulsion by novice older adults. Archives Of Physical Medicine And Rehabilitation, v.90, n.7, p.1076-1083, July 2009. Doi:

http://dx.doi.org/10.1016/j.apmr.2008.10.034.

CRAM, J.; KASMAN, G.; HOLTZ, J. Introduction to surface electromyography. Aspen: Gaithersburg, 1998.

DABONNEVILLE, M. et al. A Self-contained wireless wheelchair ergometer designed for biomechanical measures in real life conditions. Technology And Disability, v.2, n.17, p.63-76, 2005.

DELLABIANCIA, F.; PORCELLINI, G.; MEROLLA, G. Instruments and techniques for the analysis of wheelchair propulsion and upper extremity involvement in patients with spinal cord injuries: current concept review. Ligaments And Tendons Journal, v.3, n.3, p.150-156, July 2013.

DYSON-HUDSON, T.A.; KIRSHBLUM, S.C. Shoulder pain in chronic spinal cord injury. Part 1: epidemiology, etiology, and pathomechanics. The Journal Of Spinal Cord Medicine, v.27, n.1, p.4-17, Jan. 2004. Doi: http://dx.doi.org/10.1080/10790268.2004.11753724.

GAGNON, D. et al. Trunk and shoulder kinematic and kinetic and electromyographic adaptations to slope increase during motorized treadmill propulsion among manual wheelchair users with a spinal cord injury. Biomed Research International, v.2015, p.1-15, 2015. Doi: http://dx.doi.org/10.1155/2015/636319.

HARBURN, K.L.; SPAULDING, S.J. Muscle activity in the spinal cord-injured during wheelchair ambulation. American Journal Of Occupational Therapy, v.40, n.9, p.629636, Sept. 1986. Doi: http://dx.doi.org/10.5014/ajot.40.9.629.

KELLY, B.T. et al. Optimal normalization tests for shoulder muscle activation: An electromyographic study. Journal Of Orthopaedic Research, v.14, n.4, p.647-653, July 1996. Doi: http://dx.doi.org/10.1002/jor.1100140421.

KLOOSTERMAN, M.G. et al. Effect of power-assisted hand-rim wheelchair propulsion on shoulder load in experienced wheelchair users: a pilot study with an instrumented wheelchair. Medical Engineering \& Physics, v.37, n.10, p.961-968, Oct. 2015. Doi: http://dx.doi.org/10.1016/j.medengphy.2015.07.004.

Exploration of shoulder load during hand-rim wheelchair start-up with and without power-assisted propulsion in experienced wheelchair users. Clinical Biomechanics, v.34, p.1-6, May 2016. Doi: http://dx.doi.org/10.1016/j.clinbiomech.2016.02.016. 
KOONTZ, A.M.; BONINGER, M.L. Proper propulsion. Rehab Management, v.16, n.6, p.18-22, July 2003.

KOONTZ, A.M. et al. Shoulder kinematics and kinetics during two speeds of wheelchair propulsion. Journal Of Rehabilitation Research And Development, v.39, n.6, p.635649, Dec. 2002.

KOONTZ, A.M. et al. A Kinetic analysis of manual wheelchair propulsion during startup on select indoor and outdoor surfaces. The Journal Of Rehabilitation Research And Development, v.42, n.4, p.447-458, 2005. Doi: http://dx.doi.org/10.1682/jrrd.2004.08.0106.

Manual wheelchair propulsion patterns on natural surfaces during start-up propulsion. Archives Of Physical Medicine And Rehabilitation, v.90, n.11, p.19161923, Nov. 2009. Doi: http://dx.doi.org/10.1016/j.apmr.2009.05.022.

KOTAJARVI, B.R. et al. The Effect of seat position on wheelchair propulsion biomechanics. The Journal Of Rehabilitation Research And Development, v.41, n.3, p.403-414, 2004. Doi: http://dx.doi.org/10.1682/jrrd.2003.01.0008.

The Effect of visual biofeedback on the propulsion effectiveness of experienced wheelchair users. Archives Of Physical Medicine And Rehabilitation, v.87, n.4, p.510-515, Apr. 2006. Doi: http://dx.doi.org/10.1016/j.apmr.2005.12.033.

KWARCIAK, A.M. et al. Evaluation of wheelchair tire rolling resistance using dynamometer-based coast-down tests. The Journal Of Rehabilitation Research And Development, v.46, n.7, p.931-938, 2009. Doi:

http://dx.doi.org/10.1682/jrrd.2008.10.0137.

MCCASLAND, L.D. et al. Shoulder pain in the traumatically injured spinal cord patient. JCR: Journal of Clinical Rheumatology, v.12, n.4, p.179-186, Aug. 2006. Doi: http://dx.doi.org/10.1097/01.rhu.0000230532.54403.25.

MEDOLA, F.O. et al. Aspects of manual wheelchair configuration affecting mobility: a review. Journal Of Physical Therapy Science, v.26, n.2, p.313-318, 2014. Doi: http://dx.doi.org/10.1589/jpts.26.313.

MERCER, J.L. et al. Shoulder joint kinetics and pathology in manual wheelchair users. Clinical Biomechanics, v.21, n.8, p.781-789, Oct. 2006. Doi: http://dx.doi.org/10.1016/j.clinbiomech.2006.04.010.

MOSS, A.D.; FOWLER, N.E.; GOOSEY-TOLFREY, V.I. The Intra-push velocity profile of the over-ground racing wheelchair sprint start. Journal Of Biomechanics, v.38, n.1, p.15-22, Jan. 2005. Doi: http://dx.doi.org/10.1016/j.jbiomech.2004.03.022.

MULROY, S.J. et al. Effects of spinal cord injury level on the activity of shoulder muscles during wheelchair propulsion: an electromyographic study11No commercial 
party having a direct financial interest in the results of the research supporting this article has or will confer a benefit upon the author(s) or upon any organization with which the author(s) is/are associated. Archives Of Physical Medicine And Rehabilitation, v.85, n.6, p.925-934, June 2004. Doi: http://dx.doi.org/10.1016/j.apmr.2003.08.090.

NIEMINEN, H.; TAKALA, E.-P.; VIIKARI-JUNTURA, E. Normalization of electromyogram in the neck-shoulder region. European Journal Of Applied Physiology And Occupational Physiology, v.67, n.3, p.199-207, 1993. Doi: http://dx.doi.org/10.1007/bf00864215.

ORGANIZAÇÃO MUNDIAL DE SAÚDE. World report on disability. 2011. Disponível em:<www.who.int $>$. Acesso em: 20 jul. 2017.

QI, L. et al. Effect of velocity on shoulder muscle recruitment patterns during wheelchair propulsion in nondisabled individuals: pilot study. The Journal of Rehabilitation Research and Development, v.49, n.10, p.1527-1536, 2012. Doi: http://dx.doi.org/10.1682/jrrd.2011.03.0047.

REQUEJO, P.S. Effect of rear suspension and speed on seat forces and head accelerations experienced by manual wheelchair riders with spinal cord injury. The Journal of Rehabilitation Research and Development, v.45, n.7, p.985-996, Dec. 2008. Doi: http://dx.doi.org/10.1682/jrrd.2008.01.0006.

SONENBLUM, S.E.; SPRIGLE, S.; LOPEZ, R.A. Manual wheelchair use: bouts of mobility in everyday life. Rehabilitation Research And Practice, v.2012, p.1-7, 2012. Doi: http://dx.doi.org/10.1155/2012/753165.

TOLERICO, M.L. et al. Assessing mobility characteristics and activity levels of manual wheelchair users. The Journal of Rehabilitation Research and Development, v.44, n.4, p.561-571, 2007. Doi: http://dx.doi.org/10.1682/jrrd.2006.02.0017.

VAN DER WOUDE, L. et al. Measurement of wheelchair rolling resistance with a handle bar push technique. Journal Of Medical Engineering \& Technology, v.27, n.6, p.249258, Jan. 2003. Doi: http://dx.doi.org/10.1080/0309190031000096630.

VAN DRONGELEN, S. et al. Mechanical load on the upper extremity during wheelchair activities. Archives of Physical Medicine and Rehabilitation, v.86, n.6, p.1214-1220, June 2005. Doi: http://dx.doi.org/10.1016/j.apmr.2004.09.023.

VANLANDEWIJCK, Y.; THEISEN, D.; DALY, D. Wheelchair propulsion biomechanics. Sports Medicine, v.31, n.5, p.339-367, 2001. Doi: http://dx.doi.org/10.2165/00007256-200131050-00005.

VEEGER, H.E.J.; VAN DER WOUDE, L.H.V.; ROZENDAL, R.H. Load on the upper extremity in manual wheelchair propulsion. Journal of Electromyography and 
Kinesiology, v.1, n.4, p.270-280, Dec. 1991. Doi: http://dx.doi.org/10.1016/10506411(91)90014-v.

VEEGER, H.E.J.; VAN DER WOUDE, L.H.V.; ROZENDAL, R.H. Effect of handrim velocity on mechanical efficiency in wheelchair propulsion. Medicine \& Science in Sports \& Exercise, v.24, n.1, p.100-107, Jan. 1992. Doi: http://dx.doi.org/10.1249/00005768$199201000-00017$.

VEEGER, H.E.J.; ROZENDAAL, L.A.; VAN DER HELM, F.C.T. Load on the shoulder in low intensity wheelchair propulsion. Clinical Biomechanics, v.17, n.3, p.211-218, Mar. 2002. Doi: http://dx.doi.org/10.1016/s0268-0033(02)00008-6.

WALTER, J.D.; CONANT, F.S. Energy losses in tires. Tire Science and Technology, v.2, n.4, p.235-260, Nov. 1974. Doi: http://dx.doi.org/10.2346/1.2167188.

WESTGAARD, R.H. Measurement and evaluation of postural load in occupational work situations. European Journal of Applied Physiology and Occupational Physiology, v.57, n.3, p.291-304, 1988. Doi: http://dx.doi.org/10.1007/bf00635987.

YANG, Y.-S. et al. Surface electromyography activity of trunk muscles during wheelchair propulsion. Clinical Biomechanics, v.21, n.10, p.1032-1041, Dec. 2006. Doi: http://dx.doi.org/10.1016/j.clinbiomech.2006.07.006. 


\section{Anexo 1}

\section{TERMO DE CONSENTIMENTO LIVRE E ESCLARECIDO}

Você está sendo convidado como voluntário a participar da pesquisa "Análise cinemática e eletromiográfica da fase de impulsáo inicial da autopropulsão de cadeira de rodas".

Neste estudo pretendemos investigar e identificar o padrăo de movimento dos segmentos corporais cabeça, tronco, braço e antebraço durante a fase de impulsão inicial da autopropulsáo de cadeiras de rodas para colocaçáo da mesma em movimento a partir do repouso, por meio da cinemetria e eletromiografia.

O motivo que nos leva a estudar esse assunto é a necessidade de conhecer o comportamento das variáveis cinemáticas (posiçăo, velocidade e aceleraçăo) dos segmentos corporais, bem como a atividade elétrica dos músculos envolvidos na fase inicial da autopropulsão. Participarão deste estudo somente homens praticantes de handebol em cadeira de rodas, vinculados às atividades desenvolvidas no Projeto de Atividades Físicas, Esportivas e de Lazer Adaptadas a Pessoas com Deficiências-PROAFA do Núcleo de Estudos em Atividade Física Adaptada/UFSCar/CNPq. Este projeto também está vinculado ao grupo de pesquisa Biomecânica do Movimento Humano/UFSCar/CNPq.

Os atletas devem ser praticantes ativos do referido esporte, năo apresentando histórico de lesăo/disfunçăo articular persistente e/ou trauma músculo-esquelético associado aos membros superiores (incluindo tronco) no período no qual realizarão os testes de autopropulsão da cadeira de rodas. Participarăo do estudo todos que satisfizerem os requisitos acima, independentemente da etiologia e do tempo da deficiência.

Os resultados obtidos a partir dessas avaliações poderăo contribuir para a mel hor compreensão das características de movimentos de cada segmento e articulaçăo, bem como dos níveis de ativação neuromuscular decorrentes da fase de impulsão inicial para colocaçăo da cadeira de rodas em movimento a partir do repouso.

\section{Para este estudo adotaremos o(s) seguinte(s) procedimento(s):}

Serão mensuradas as seguintes variáveis antropométricas: peso, estatura, circunferências e comprimentos do braço e antebraço, circunferência da cintura, abdômen, envergadura (distância entre o dedo médio esquerdo e o dedo médio direito, com os braços abertos), dobras cutâneas no terço medial do bíceps e tríceps. O manuseio dos equipamentos para essas medidas (estadiômetro, balança, fita antropométrica, adipômetro, paquímetro) ficará sob a responsabilidade do pesquisador e/ou do bolsista de iniciação científica devidamente treinado. As avaliaçōes serão realizadas nas dependências dos laboratórios dos departamentos de Educaçâo Física e Motricidade Humana e de Fisioterapia da Universidade Federal de Sâo Carlos. No momento da avaliaçâo da composição corporal, você deverá usar mínimo de roupa possível e todos os equipamentos estarāo em perfeitas condiçōes de uso e calibre. As mensuraçōes das variáveis antropométricas seguirão padrōes internacionais.

Para o teste da contração voluntária isométrica máxima (CVM) você será orientado a permanecer confortavelmente sentado em sua própria cadeira de rodas usada nos treinamentos, a qual estará devidamente fixada a um apoio através de um cabo de aço ligado a uma célula de carga (tensiômetro). Você, desta forma, deverá envolver os arcos das rodas com as mãos enquanto o tensiômetro será ajustado pelo examinador.

Você executará três tentativas de esforço estático de 6 segundos, intervaladas por dois minutos, a fim de se evitar a instalaçâo de fadiga muscular acumulada. Os sinais de eletromiografia registrados no modo de CVM serão usados como padrão de neuroativação máxima da musculatura envolvida quando da comparação às atividades musculares pertinentes à execução do movimento de propulsão propriamente dito. Será considerado padrão de sinal eletromiográfico aquele que corresponder à tentativa que registrar o maior valor indicado pela célula de carga.

Uma vez na posição correta, você executará o esforço máximo nos testes, com orientaçōes verbais de incentivo por parte do examinador durante os 6 segundos (exemplo: um, dois, três, JÁ!.... FORÇA!... FORÇA!... FORÇA!... ISSO!... relaxa....).

A atividade elétrica muscular será registrada juntamente com o registro da força. Anteriormente ao início de cada avaliação será permitido que você se familiarize com o equipamento e com o protocolo requerido. Anteriormente a cada avaliaçâo haverá a preparaçāo da pele, na regiâo onde o eletrodo será posicionado, com raspagem dos pelos e limpeza da área com álcool a 70\%. Em seguida os eletrodos serāo posicionados sobre os seguintes músculos do braço e antebraço do membro dominante: deltóide anterior (DA), deltóide medial (DM), deltóide posterior (DP), peitoral maior (PM), trapézio superior (TU), bíceps braquial (BB), tríceps braquial (TB), flexor radial do punho (FRP). Os eletrodos serāo fixados com tiras esparadrapo, para evitar seu deslocamento durante a realização dos procedimentos. $O$ eletrodo de referência, monopolar, será posicionado no olécrano da ulna (cotovelo) conforme indicaçōes de uso do referido equipamento.

Após um intervalo de 20 minutos depois da execução do teste de CVM, para minimizar os efeitos de fadiga acumulada, você executará uma sequência de no mínimo 5 e máximo de 10 movimentos de propulsâo, partindo da posição de repouso até completar a extensâo total dos membros superiores, deslocando assim, a cadeira de rodas para frente. Entre as tentativas haverá um intervalo de ao menos um minuto para recuperação e ajustes das câmeras. Os arcos das rodas deverão ser impulsionados com o 
máximo de esforço possível, compatível com sua condição individual, em um único movimento. Você deverá percorrer uma trajetória retilínea ao menos por 3 metros, para garantir a equivalência das açōes dos membros dominantes e nâo-dominantes. A posição da mão no arco de roda nâo será pré-definida, sendo respeitada a posição na qual você se sentir confortável, conforme sua experiência na condução da cadeira de rodas, desde que possa exercer o máximo de esforço possível para a realização do impulso inicial.

Esses movimentos de propulsão serâo executados numa área devidamente instrumentada com filmadoras as quais registrarâo a posição, velocidade e aceleração de cada segmento corporal. Para que as câmeras possam registrar essas variáveis cinemáticas, você receberá alguns marcadores (esferas de isopor ${ }^{\circledR}$, em velcro ${ }^{\circledR}$ preto com adesivos) os quais serâo devidamente fixados nas seguintes proeminências ósseas e inserçōes musculares de interesse, a fim de definirmos os principais segmentos corporais: Vértex do osso parietal; Regiâo lateral do arco zigomático direita; Região lateral do arco zigomático esquerda; Processo espinhoso da sétima vértebra cervical; Epicôndilo lateral direito; Epicôndilo lateral esquerdo; Inserção do músculo deltóide direito; Inserção do músculo deltóide esquerdo; Tubérculo menor do úmero direito; Tubérculo menor do úmero esquerdo; Acrômio direito; Acrômio direito esquerdo; Espinha ilíaca pósterosuperior direita; Espinha ilíaca póstero-superior direita esquerda; Epicôndilo lateral direito; Epicôndilo lateral esquerdo; Processo estilóide do rádio direito; Processo estilóide do rádio esquerdo; Processo estilóide da ulna direita, e Processo estilóide da ulna esquerda.

Para participar deste estudo você năo terá nenhum custo, nem receberá qualquer vantagem financeira. Você será esclarecido sobre o estudo em qualquer aspecto que desejar e estará livre para participar ou recusar-se a participar. Poderá retirar seu consentimento ou interromper a participação a qualquer momento. A sua participaçăo é voluntária e a recusa em participar não acarretará qualquer penalidade ou modificaçăo na forma em que é atendida pelo pesquisador. O pesquisador irá tratar a sua identidade com padrões profissionais de sigilo. Você năo será identificado em nenhuma publicaçăo que possa resultar deste estudo. Este estudo apresenta risco mínimo, isto é, o mesmo risco existente em atividades rotineiras como conversar, tomar banho, ler, etc. ou mesmo ao conduzir sua cadeira de rodas nas atividades do cotidiano Apesar disso, você tem assegurado o direito a ressarcimento ou indenizaçăo no caso de quaisquer danos eventualmente produzidos pela pesquisa.

Os resultados da pesquisa estarăo à sua disposiçấo quando finalizada. Seu nome ou o material que indique sua participação nâo será liberado sem a sua permissão. Os dados e instrumentos utilizados na pesquisa ficarăo arquivados com o pesquisador responsável por um período de 5 anos, e após esse tempo serăo destruídos. Este termo de consentimento encontra-se impresso em duas vias, sendo que uma cópia será arquivada pelo pesquisador responsável, e a outra será fornecida a você.

Eu, portador do Documento de Identidade fui informado dos objetivos do presente estudo de maneira clara e detalhada e esclareci minhas dúvidas. Sei que a qualquer momento poderei solicitar novas informações e modificar minha decisão de participar se assim o desejar.

Declaro que concordo em participar desse estudo. Recebi uma cópia deste termo de consentimento livre e esclarecido e me foi dada a oportunidade de ler e esdarecer as minhas dúvidas. Declaro que entendi os objetivos, riscos e benefícios de minha participação na pesquisa e concordo em participar.

O pesquisador me informou que o projeto foi aprovado pelo Comitê de Ética em Pesquisa em Seres Humanos da UFSCar que funciona na Pró-Reitoria de Pós-Graduaçăo e Pesquisa da Universidade Federal de São Carlos, localizada na Rodovia Washington Luiz, Km. 235 - Caixa Postal 676 - CEP 13.565-905 Săo Carlos - SP - Brasil.Fone (16) 3351-8110. Endereço eletrônico: cephumanos@power.ufscar.br

de de 20

Assinatura do participante

Em caso de dívidas com respeito aos aspectos éticos deste estudo, você poderá consultar, além do Comitê de Ética em Pesquisa em Seres Humanos da UFSCar:

PESQUISADOR RESPONSÁVEL: JOSÉ MARQUES NOVO JÚNIOR

ENDEREÇO: AV. JOSÉ GONÇALVS CARNEIRO, 520 - SANTA MÓNCA

SAO CARLOS/SP - CEP: 13561-220

FONE:(16)8117-5184E-MAIL: marques.novojr@ufscar.br 


\section{Anexo 2}

Esta seção apresenta sinais eletromiográficos brutos de cada grupo muscular registrados de 10 propulsões a partir do repouso.

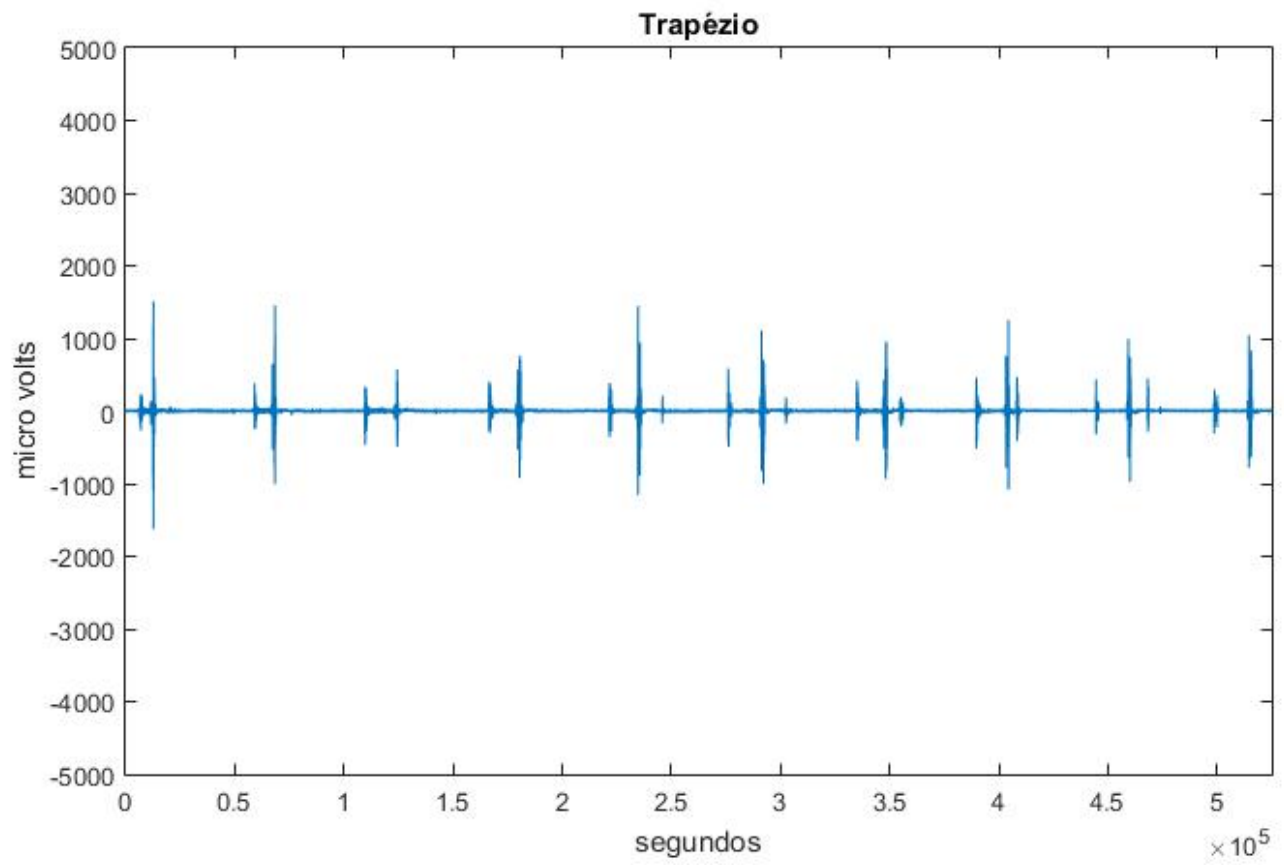

Legenda: Sinal eletromiográfico bruto do T do participante 3.

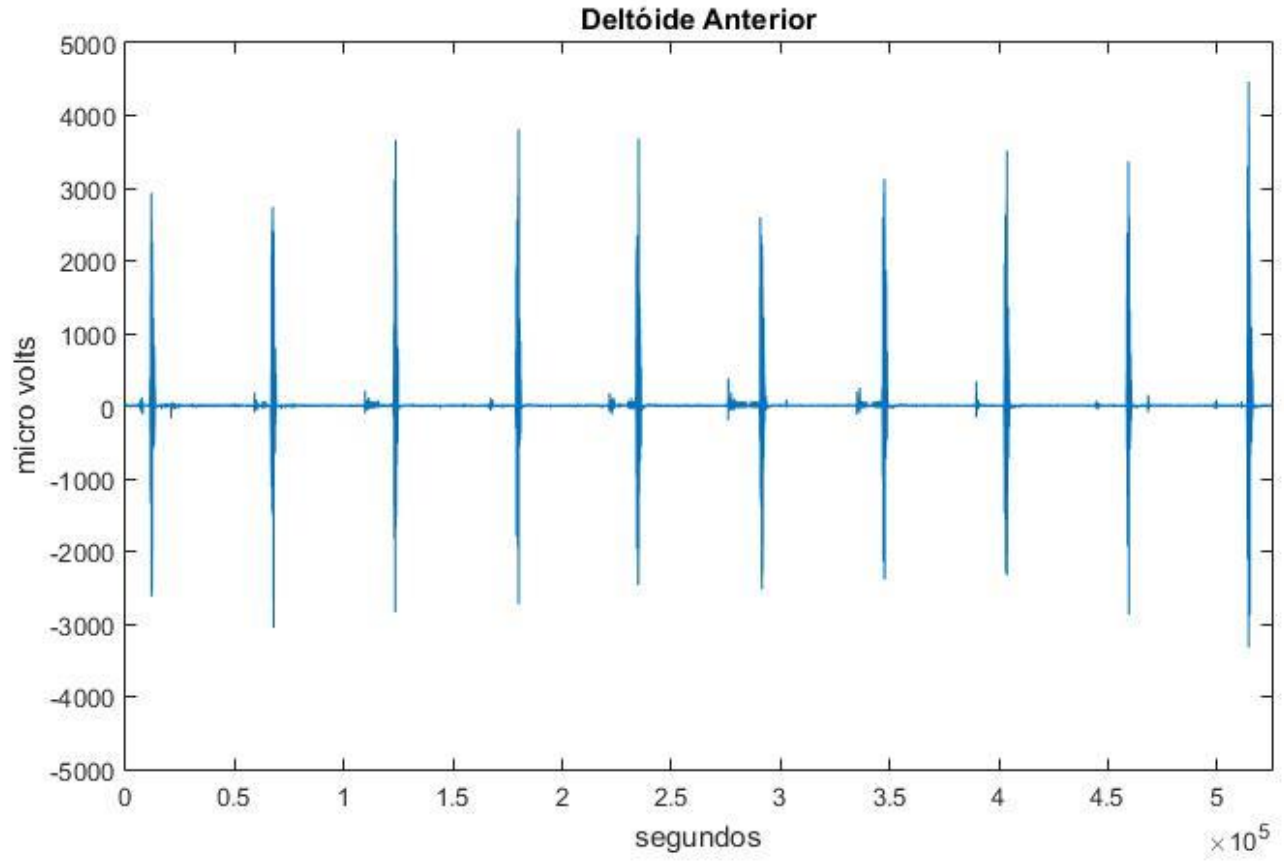

Legenda: Sinal eletromiográfico bruto do DA do participante 3. 


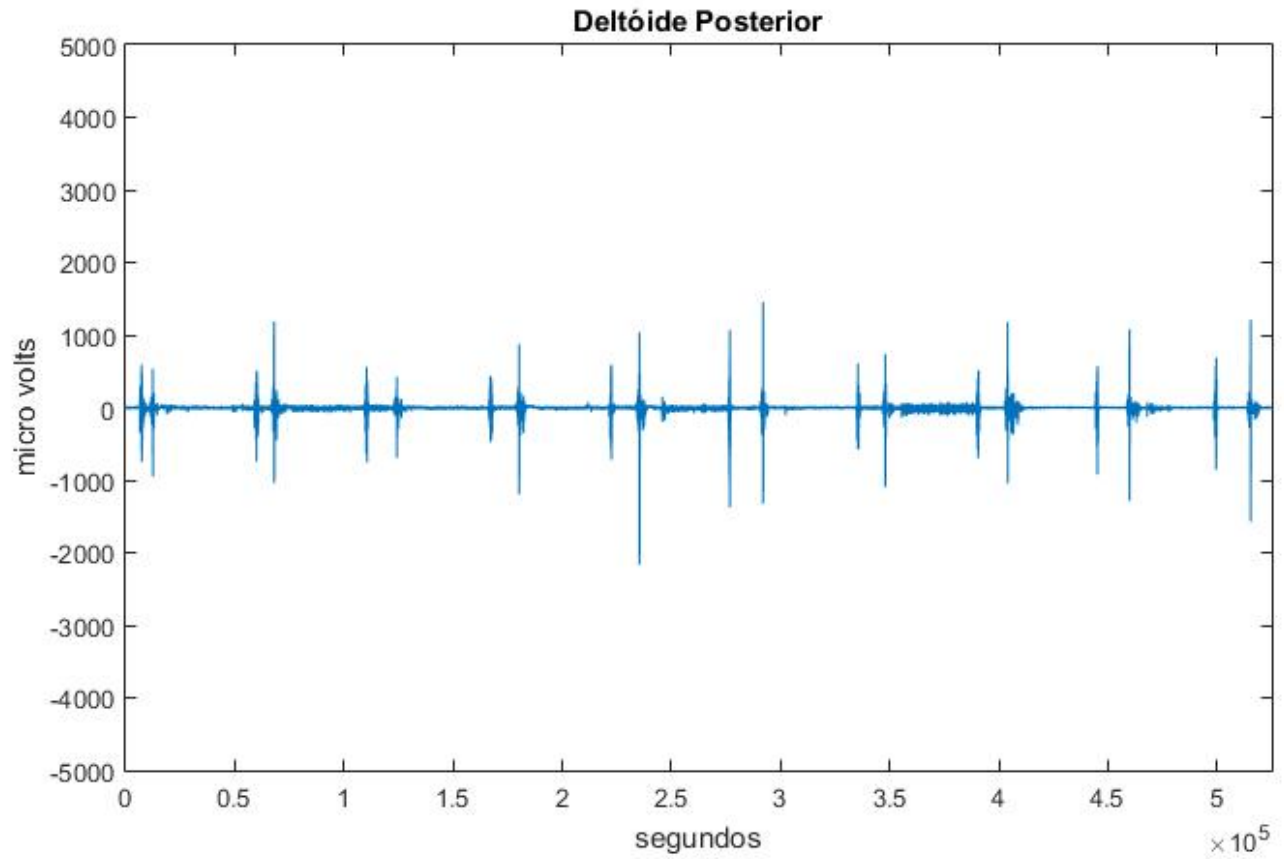

Legenda: Sinal eletromiográfico bruto do DP do participante 3.

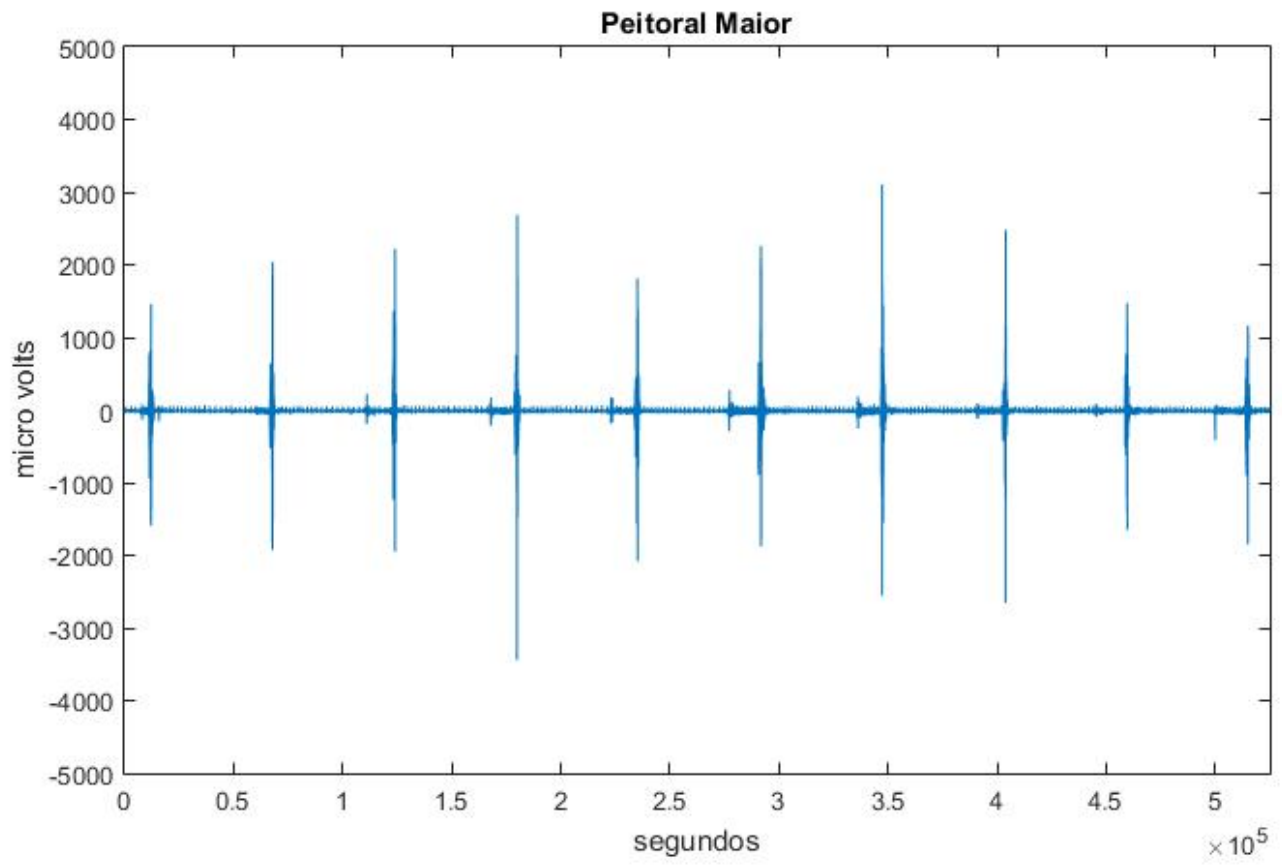

Legenda: Sinal eletromiográfico bruto do PM do participante 3. 


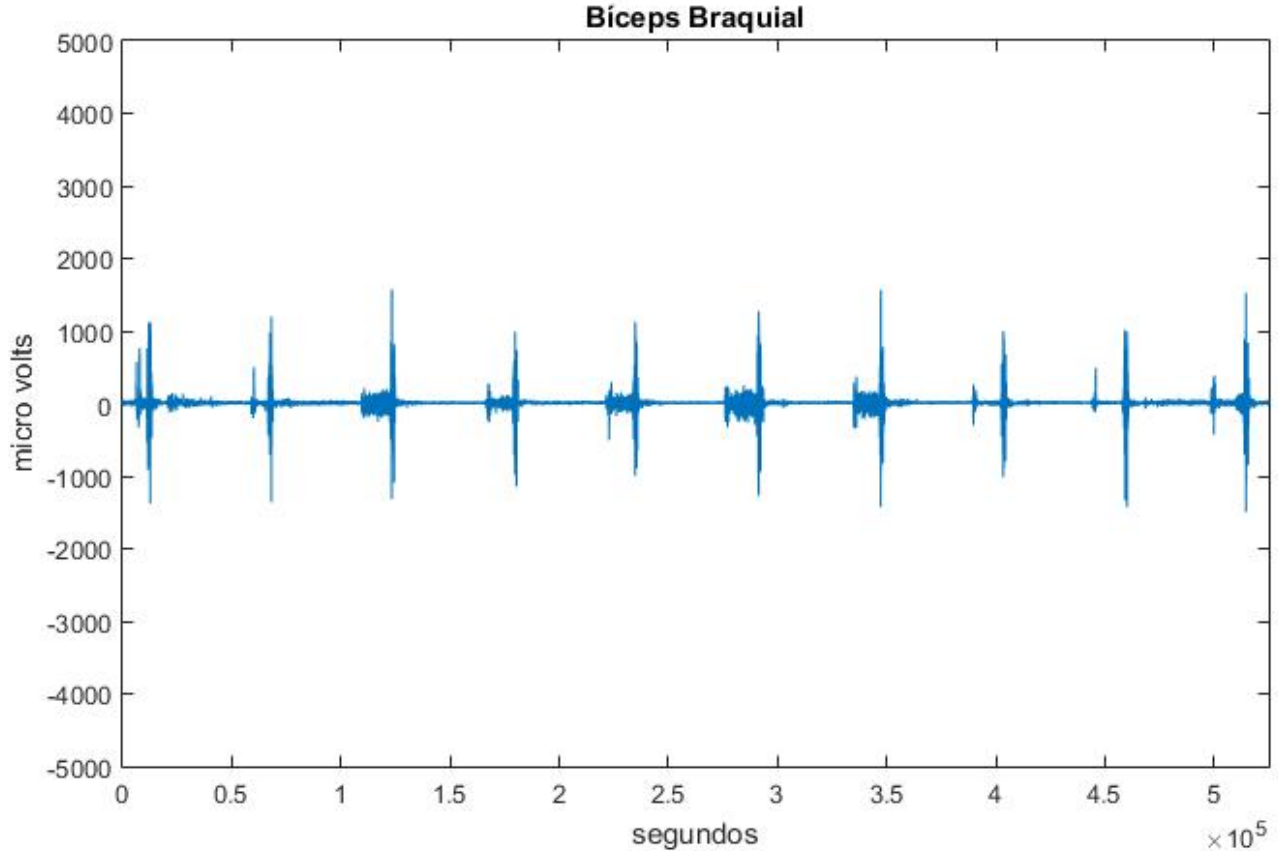

Legenda: Sinal eletromiográfico bruto do BB do participante 3.

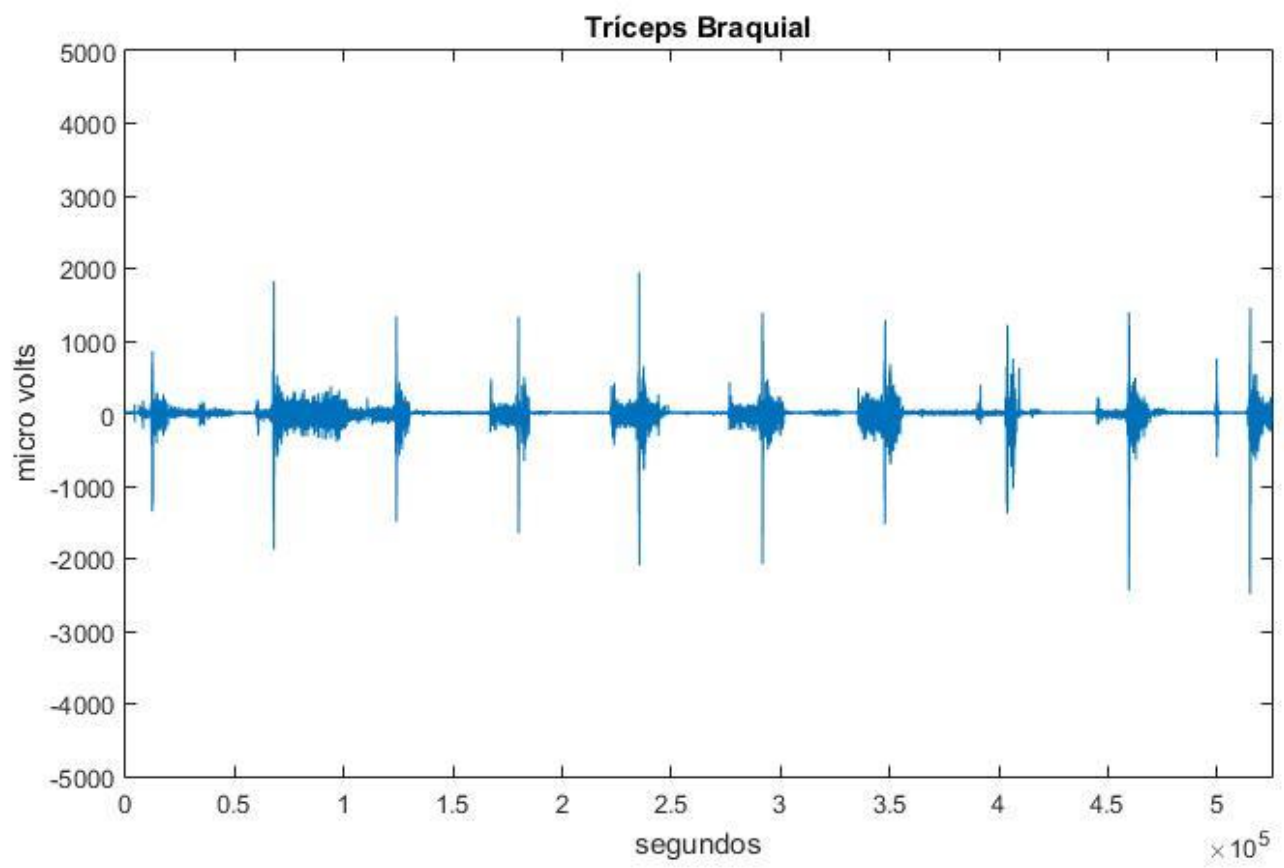

Legenda: Sinal eletromiográfico bruto do TB do participante 3. 


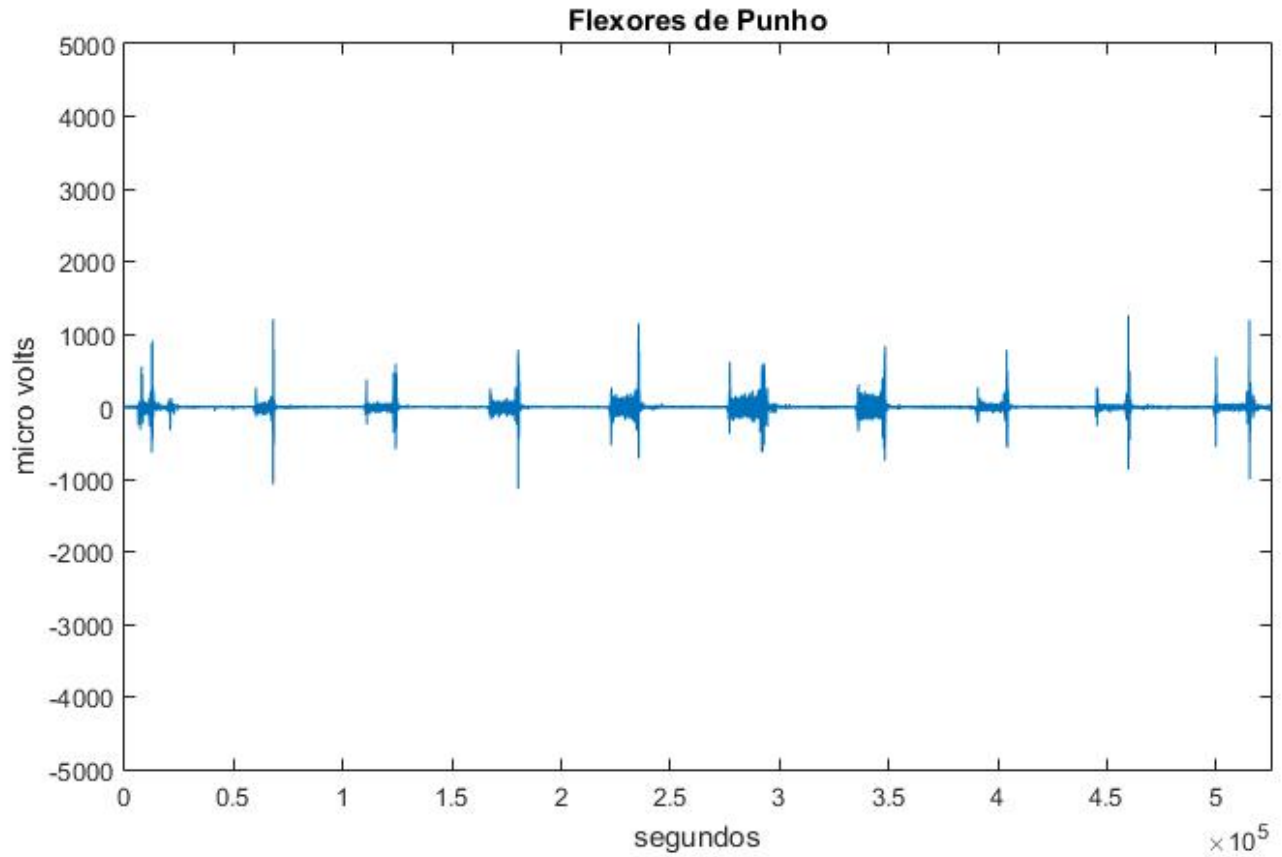

Legenda: Sinal eletromiográfico bruto do FP do participante 3.

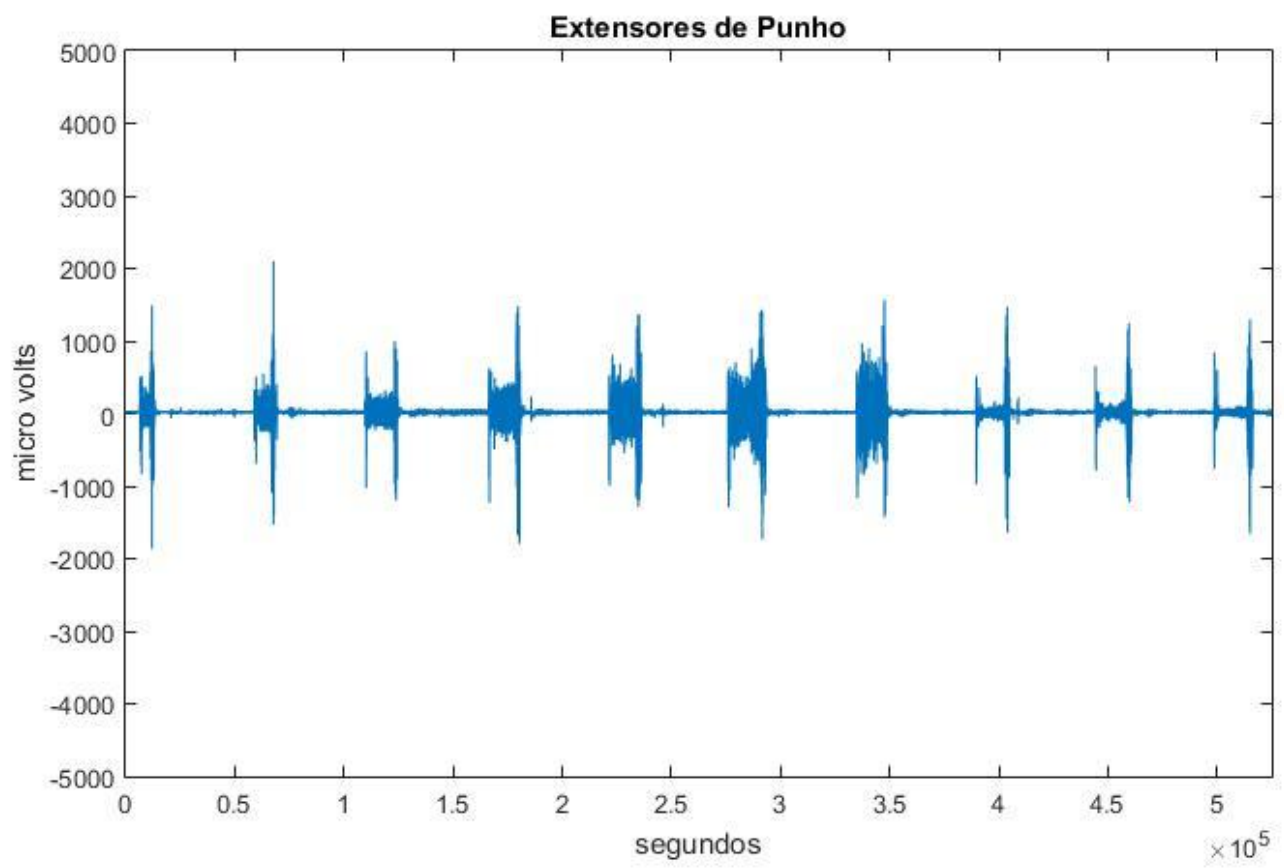

Legenda: Sinal eletromiográfico bruto do EP do participante 3. 